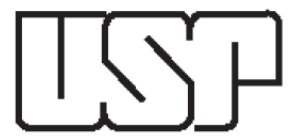

UNIVERSIDADE DE SÃO PAULO

INSTITUTO DE RELAÇÕES INTERNACIONAIS

PROGRAMA DE PÓS-GRADUAÇÃO EM RELAÇÕES

INTERNACIONAIS

KAREN KATARINE MIZUTA

ROGUE STATE E ARMAS NUCLEARES: RACIONALIDADE DOS ATORES NA AQUISIÇÃO DE ARMAS NUCLEARES NO PÓS-GUERRA FRIA

São Paulo

2013 


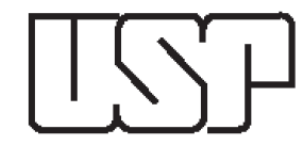

\author{
UNIVERSIDADE DE SÃO PAULO \\ INSTITUTO DE RELAÇÕES INTERNACIONAIS \\ PROGRAMA DE PÓS-GRADUAÇÃO EM RELAÇÕES \\ INTERNACIONAIS
}

\title{
ROGUE STATE E ARMAS NUCLEARES: RACIONALIDADE DOS ATORES NA AQUISIÇÃO DE ARMAS NUCLEARES NO PÓS-GUERRA FRIA
}

Karen Katarine Mizuta

\begin{abstract}
Artigos apresentados ao Programa de PósGraduação em Relações Internacionais do Instituto de Relações Internacionais da Universidade de São Paulo para obtenção do título de Mestre em Relações Internacionais.
\end{abstract}

Orientação: Prof. Dr. Rafael A. D. Villa.

São Paulo 
FOLHA DE APROVAÇÃO

Karen Katarine Mizuta

\section{ROGUE STATE E ARMAS NUCLEARES: RACIONALIDADE DOS ATORES NA AQUISIÇÃO DE ARMAS NUCLEARES NO PÓS-GUERRA FRIA}

Artigos apresentados ao Programa de Pós-Graduação em Relações Internacionais do Instituto de Relações Internacionais da Universidade de São Paulo, sob orientação do Prof. Dr. Rafael A. D. Villa, para obtenção do título de Mestre em Relações Internacionais.

Aprovado em:

\section{Banca Examinadora}

Prof. Dr. Rafael Antônio Duarte Villa (Orientador)

Instituição: IRI/USP

Assinatura:

Prof. Dr.:

Instituição:

Assinatura:

Prof. Dr.:

Instituição:

Assinatura: 


\section{AGRADECIMENTOS}

Aos meus queridos pais, Akira Mizuta e Elisabete da Silva Mizuta, e às minhas queridas irmãs, Erin e Darien, por sua fundamental presença em minha vida e apoio, mesmo quando distantes fisicamente.

Ao meu amado Marcelo Aydar Sandoval, meu marido, por seu apoio incondicional às minhas decisões; por sua paciência e compreensão durante todo esse processo; por seu carinho e encorajamento nos momentos difíceis; e por todo o tempo que já estamos juntos e pela vida inteira que ainda está por vir.

Ao Prof. Dr. Rafael A. Duarte Villa pelos valiosos conselhos e orientações durante o programa de Mestrado e pelo grande aprendizado tanto nas pesquisas quanto em sala de aula.

Ao Instituto de Relações Internacionais, IRI-USP, seu corpo de professores e funcionários, em especial às meninas da secretaria, Berbel e Giselle.

À Stella do NUPRI pelo auxílio ao longo do mestrado.

Às amigas de longa data, Ana Júlia Mazzotti e Mariana Buendia Sabbagh, pela amizade, pelas inúmeras conversas motivadoras e pelo incentivo na carreira acadêmica.

À amiga Isabela Gerbelli Garbin, que muito me auxiliou na carreira acadêmica durante estes anos de mestrado. À amiga Adriane Camargo, pelos momentos acadêmicos compartilhados e pelo apoio.

À minha nova família, que ganhei após o casamento, pelo apoio, estímulo e "jantares delivery" feitos com carinho pela Tatiana e Tia Edna, quando me faltava tempo.

À Fundação de Amparo à Pesquisa do Estado de São Paulo, FAPESP, pelo apoio financeiro que possibilitou minha dedicação exclusiva à pesquisa, durante os anos do programa de pós-graduação. 


\section{RESUMO}

Desde o fim da Guerra Fria, os Estados Unidos promoveram a noção da existência de "Rogue States", denominando-os "novos inimigos". No entanto, o termo confere muitas controvérsias em torno de sua definição, principalmente dos critérios que conferem o rótulo a tais atores. A irracionalidade na tomada de decisões e a busca pela aquisição de armas nucleares se apresentam como características fundamentais. Através da análise dos discursos americanos sobre rogue states, e sob a perspectiva construtivista, podemos depreender que o discurso foi utilizado como forma de corroborar as ações norte-americanas em relação a estes países, ao mesmo tempo em que moldavam as próprias estratégias americanas, uma vez que os atos de fala conferem uma ação em si. As ações tomadas diante de uma situação são definidas a partir da percepção deste fato e do significado que o ator dará a ele. Assim, o apontamento de certos países como sendo Rogue States pelos Estados Unidos serviu para distinguir entre os países do Sistema Internacional "aqueles que deveriam ser combatidos". Alguns críticos do termo afirmam que o critério de racionalidade aplicado a estados como Coreia do Norte e Irã é muito mais rigoroso que aquele aplicado aos demais estados, mesmo a USSR durante a Guerra Fria. O presente trabalho pretende avaliar o surgimento do termo rogue state e sua utilização pelo governo norte-americano como política oficial. Através de dois artigos, busca-se entender a construção do conceito de rogue state, levando-se em consideração as teorias construtivistas, principalmente dos teóricos da chamada virada linguística. Uma vez que o debate da irracionalidade está diretamente ligado a busca pela obtenção de armas nucleares - critério-chave para o apontamento como rogue-, pretende-se também avaliar as suposições para tal classificação através da investigação dos programas nucleares dos dois países na atualidade que estão no centro do debate nuclear- Irã e Coreia do Norte.

Palavras-chave: rogue state, política externa americana, construtivismo, irracionalidade, armas nucleares 


\begin{abstract}
Since the end of the Cold War, the United States promoted the notion of the existence of "Rogue States", designating them as "new enemies". However, the term presents many controversies surrounding its definition, especially about the criteria that confer the label to such actors. The irrationality in decision making and the pursuit of nuclear weapons are presented as the core characteristics of the concept. Through the analysis of American discourses on rogue states, and under the constructivist perspective, one can infer that the speech was used as a way of corroborating the U.S. actions towards these countries, while that shaped the American strategies themselves, once the speech acts are an action itself. Actions taken towards a situation are defined according to the perceptions and meaning the actor will give to it. Thus, the indication of certain countries as Rogue States by the United States served to distinguish among the countries of International System "those who should be fought". Some critics of the term argue that the criterion of rationality applied to states like North Korea and Iran is much more rigorous than the one applied to other states, even the USSR during the Cold War. This work intends to evaluate the emergence of the term rogue state and its use by the U.S. government as an official policy. Through two articles, we seek to understand the construction of the rogue state concept, taking into account the constructivist theories, especially the theory of so-called linguistic turn. Since the discussion of irrationality is directly linked to the search for acquiring nuclear weapons - key characteristic of a rogue-, it also intends to evaluate the assumptions for such classification by investigating the nuclear programs of both countries currently at the center of the nuclear debate -Iran and North Korea.
\end{abstract}

Keywords: rogue state, American foreign policy, constructivism, irrationality, nuclear weapons 


\section{SUMÁRIO}

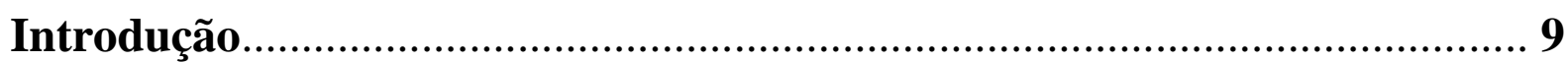

\section{ARTIGO 1. ROGUE STATE: O CONCEITO E SUA UTILIZAÇÃO SOB A ÓTICA CONSTRUTIVISTA}

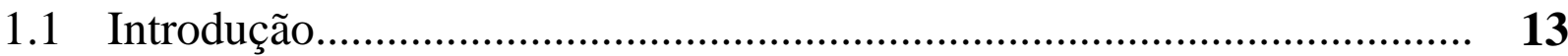

1.2 O surgimento do Conceito "Rogue State" ............................................. 15

1.3 Percepção dos Rogues: construtivismo como base teórica....................... 22

1.4 A imagem do Rogue State na Política Externa Americana..................... 26

1.5 Considerações Finais........................................................................ 36

1.6 Referências Bibliográficas.................................................................. 39

ARTIGO 2. ROGUE STATE E ARMAS NUCLEARES: RACIONALIDADE DOS ATORES NA AQUISIÇÃO DE ARMAS NUCLEARES NO PÓS-GUERRA

2.1 Rogue State: historicidade e percepções.................................................... 44

2.2 Rogue State como ator irracional.......................................................... 47

2.3 Programa nucleares dos rogues states................................................ 52

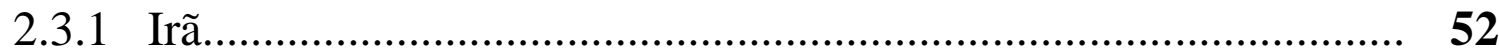

2.3.2 Coreia do Norte.................................................................... 55

2.4 Considerações Finais.......................................................................... 59

2.5 Referências Bibliográficas................................................................... 61 



\section{INTRODUÇÃO}

O presente trabalho pretende avaliar o conceito de Rogue State e suas implicações na política externa americana. Por estar diretamente ligado ao debate nuclear e o apontamento do ator como sendo irracional, o termo rogue state também servirá como pano de fundo para o analisar os programas nucleares do Irã e Coreia do Norte.

Este trabalho acompanha a proposta de avaliação do Programa de Pós-Graduação em Relações Internacionais do IRI-USP, sendo apresentado em dois artigos relacionados entre si. Apesar de não se organizar no formato tradicional de dissertação de mestrado, o trabalho permite a exposição do conteúdo desenvolvido e pesquisado durante o programa de Mestrado. O novo formato também contribui para a possível publicação dos artigos, produto final da pesquisa.

O primeiro artigo, intitulado "Rogue State: O conceito e sua utilização sob a ótica construtivista", pretende avaliar o surgimento do termo rogue state e sua utilização pelo governo norte-americano como política oficial. Levando-se em consideração as teorias construtivistas, principalmente dos teóricos da chamada virada linguística, o artigo analisará o discurso americano em relação aos países denominados Rogues. Desde o fim da Guerra Fria, os Estados Unidos promoveram a noção da existência de Rogue States, denominando-os "novos inimigos". No entanto, o termo confere muitas controvérsias em torno de sua definição. As ações tomadas diante de uma situação são definidas a partir da percepção deste fato e do significado que o ator dará a ele. Sob a perspectiva construtivista, podemos depreender que o discurso foi utilizado como forma de corroborar as ações norte-americanas em relação a estes países, ao mesmo tempo em que moldavam as próprias estratégias americanas, uma vez que os atos de fala conferem uma ação em si.

O segundo artigo, intitulado "Rogue State e Armas Nucleares: Racionalidade dos Atores na aquisição de armas nucleares no pós-Guerra Fria”, permite analisar os programas nucleares de dois países, Irã e Coreia do Norte. Com o fim da Guerra Fria, os Estados Unidos procuram apontar certos países como sendo Rogue State, termo que serviu para distinguir, entre os países do Sistema Internacional, aqueles que deveriam ser combatidos. No entanto, o conceito de rogue state é discutível, principalmente em relação aos critérios que confeririam um país como tal. A irracionalidade na tomada de decisões e a busca pela aquisição de armas nucleares são 
características fundamentais. Alguns críticos do termo afirmam que o critério de racionalidade aplicado a estados como Coreia do Norte e Irã é muito mais rigoroso que aquele aplicado aos demais estados, mesmo a USSR durante a Guerra Fria. Uma vez que o debate da irracionalidade está diretamente ligado a busca pela obtenção de armas nucleares, este artigo pretende avaliar as suposições para tal classificação através da investigação dos programas nucleares dos dois países que na atualidade estão no centro dos debates- Irã e Coreia do Norte. 


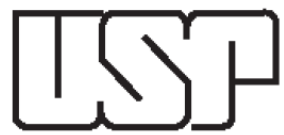

UNIVERSIDADE DE SÃO PAULO

INSTITUTO DE RELAÇÕES INTERNACIONAIS

PROGRAMA DE PÓS-GRADUAÇÃO EM RELAÇÕES

INTERNACIONAIS

Karen Katarine Mizuta

ROGUE STATE: O CONCEITO E SUA UTILIZAÇÃO SOB A ÓTICA CONSTRUTIVISTA

São Paulo

2013 


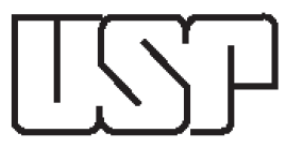

UNIVERSIDADE DE SÃO PAULO

INSTITUTO DE RELAÇÕES INTERNACIONAIS

PROGRAMA DE PÓS-GRADUAÇÃO EM RELAÇÕES

INTERNACIONAIS

\section{ROGUE STATE: O CONCEITO E SUA UTILIZAÇÃO SOB A ÓTICA CONSTRUTIVISTA}

Karen Katarine Mizuta

Primeiro artigo apresentado ao Programa de Pós-Graduação em Relações Internacionais do Instituto de Relações Internacionais da Universidade de São Paulo como parte dos requisitos para obtenção do título de Mestre em Relações Internacionais.

Orientação: Prof. Dr. Rafael A. D. Villa.

São Paulo 


\section{Rogue States: o conceito e sua utilização sob a ótica construtivista}

\section{Introdução}

O termo Rogue State ${ }^{1}$ cunhado por policymakers americanos confere muitas controvérsias em torno de sua definição, principalmente dos critérios que determinam o grupo dos "rogues": a busca pela obtenção e pelo desenvolvimento - ou já a posse - de Armas de Destruição em Massa $^{2}$ (AMD) e o apoio ao terrorismo são os critérios mais comumente utilizados. O Governo Bush definiu os Rogue States como sendo aqueles Estados que

[...] brutalizam seu próprio povo e desperdiçam seus recursos naturais em favor de ganhos pessoais de seus governantes, não demonstram nenhuma consideração para com as leis internacionais, são determinados à adquirir armas de destruição em massa, apoiam terrorismo mundo afora, rejeitam valores humanos básicos e odeiam os Estados Unidos e tudo que este defendem. (NSS, 2002, p. 13, tradução nossa)

A estrutura semântica do termo rogue nos mostra a sua utilização dentro do contexto da política externa americana: segundo o dicionário Cambridge ${ }^{3}$ o verbete rogue apresenta os seguintes significados: como adjetivo, toma o significado de algo/alguém que se comporta de maneira não esperada ou de uma maneira anormal, frequentemente de maneira destrutiva; ou ainda um animal perigoso que vive à parte do resto do seu grupo ou bando. $\mathrm{O}$ termo tem sua origem no latim derivando do termo "Rogare", denotando originalmente um vagante preguiçoso, ocioso, sem valor, sem princípios; desde o início empregado de forma pejorativa. Robert I.Rotberg afirma:

Da mesma forma, durante o século 20, havia pouca certeza sobre o significado do título designado por Washington. "Rogue" simplesmente não pertencia à família das nações. Seus métodos de operação estranhos, imorais e perversos na arena global, os colocam fora das fronteiras da mesma. (ROTBERG, 2007, p. 8, tradução nossa)

\footnotetext{
${ }^{1}$ O termo Rogue State pode ser traduzido para o português como "Estado delinquente", "Estado pária", "Estado bandido", o que demonstra a fragilidade deste termo. No presente artigo, o termo será utilizado no original em inglês, a fim de se evitar qualquer perda de significado por tradução, uma vez que se pretende discutir sua formação.

${ }^{2}$ Inclui-se em armas de destruição em massa, armas químicas, biológicas e nucleares.

${ }^{3}$ Cambridge On-line Dictionary em http://dictionary.cambridge.org/define.asp?key=98658\&dict=CALD
} 
Um rogue state seria um outsider, um outlaw - "um fora da lei" - do Sistema Internacional de Estados, um ator que ameaçaria a ordem do mesmo.

Ainda que a ideia de rogue tenha surgido durante a Guerra Fria, de acordo com alguns estudiosos (LITWAK 2000, SENN 2008, HOYT 2000), sua utilização foi concretizada na década de noventa. Na década de 1970, termos como "pariah state" e "outlaw state" foram invocados por policymakers americanos para designar países que possuíam comportamento “delinquente" (LITWAK, 2000, p. 377). Faz-se necessário ressaltar que neste momento, esses termos se referiam exclusivamente ao comportamento interno dos países, fazendo objeção aos seus regimes e suas ações para com seus próprios povos e não sua conduta internacional. Dentre os países que compunham o grupo dos países denominados "párias" estavam o Camboja na administração de Pol Pot, a Uganda de Idi Amin e a África do Sul sob o regime Apartheid. Posteriormente, o conceito de rogue state deixa de ser baseado somente no critério de comportamento interno, diretamente ligado ao pensamento tradicional da política americana, e passa a designar o comportamento dos atores em suas relações externas.

Apesar do uso do termo por policymakers americanos como forma de designar países que violam as normas internacionais, o conceito não possui base no direito internacional (LITWAK, 2000, p. 47). Sendo um reflexo das preferências políticas dos Estados Unidos, seu uso ao longo do pós-Guerra Fria, quando o conceito foi moldado, foi criticado por muitos analistas que o consideram "analiticamente fraco e altamente subjetivo", ou em outras palavras "simplesmente [uma] taquigrafia para um pequeno grupo de Estados ameaçando os interesses norte-americanos em regiões-chave" (LITWAK, 2000, p. 47, tradução nossa).

A partir da investigação dos discursos de autoridades dentro do aparato estatal norteamericano, das publicações oficias deste governo e suas interações com os atores, o artigo analisará o surgimento do conceito rogue state dentro do vocabulário de decision-makers americanos e sua interpenetração na política externa americana sob a ótica do construtivismo, como forma de melhor compreender a construção desta rotulação e a percepção que os Estados Unidos possuem de determinados Estados do sistema internacional. 


\section{O surgimento do conceito "Rogue State"}

O período do Pós-Guerra Fria serviu como contexto para a elaboração e concretização do conceito de Rogue State dentro do pensamento político norte-americano. Com a queda do Muro de Berlim e a dissolução da URSS em 1991, o inimigo desaparece, dando espaço a novos tipos de ameaças. Ao mesmo tempo que o sistema internacional presenciava o fim da Guerra Fria, houve a eclosão de uma guerra de fato (hot war) na região do Golfo Pérsico (LITWAK, 2000, p. 19).

Durante a Administração de George H. W. Bush (41 ${ }^{\circ}$ Administração), houve o reconhecimento de que ameaças regionais poderiam representar problemas para os interesses Americanos no exterior. Apesar de o termo não ter sido utilizado oficialmente por este governo, o então secretário de defesa Richard Cheney mostrou preocupação com "aspirantes a hegemonias regionais" no momento da Guerra do Golfo I. "Estados com comportamentos imprevistos" - os "Iraques" - tornar-se-iam o foco da atenção da política externa. O desenvolvimento de uma nova estratégia de contenção diferente da utilizada durante a Guerra Fria contra um único inimigo conhecido foi sugerido por Cheney (MISLAN, 2007, p. 3): havia a necessidade de uma transformação da vasta força da era da Guerra Fria planejada para deter a agressão Soviética em uma força capaz de lutar em duas frentes regionais contra ameaças apresentadas por rogue states.

No entanto, é a partir da Administração Clinton que o termo será oficialmente utilizado pelo governo americano. Segundo Anthony Lake, assessor da Segurança Nacional durante a presidência de Clinton, como única superpotência, os EUA teriam a incumbência e "responsabilidade de desenvolver uma estratégia a neutralizar, conter e através de seleção persuasiva tentar transformar esses 'backlashs' em Estados constitutivos do Sistema Internacional" (LAKE, 1994).

O surgimento do termo é controverso. Segundo Michael Klare (1995, p. 25), com o colapso da União soviética faz-se necessário o apontamento de um "novo inimigo" com o qual os EUA devem se preocupar: a ameaça rogue, apesar de difusa, confere esse novo inimigo justificando os gastos militares do pós-Guerra Fria, tão altos quanto o da antiga era. Além disso, 
a justificativa deveria recair também sobre a expansão crescente da presença militar americana no mundo.

Klare considera ser o termo rogue state necessário para a coesão de uma grandiosa estratégia do Pós-Guerra Fria: era necessário criar dentro do aparato político americano uma maneira do Departamento de Defesa justificar seus gastos e orçamento com forças militares frente ao Congresso Nacional americano. Essas rivalidades entre Departamentos de Estados levou a "construção de uma nova demonologia baseada em potências do Terceiro Mundo equipadas com Armas de Destruição em Massa" (KLARE, 1995, p. 25, tradução nossa).

Robert Litwak (2000), entretanto, não considera que o surgimento do termo tenha sido dentro do aparato político do Departamento de Defesa. O autor aponta a utilização de termos correlatos como "pariah" ou "outlaw states" durante as décadas da Guerra Fria, com o propósito de designar países com comportamento interno delinquente, como mencionado anteriormente. Somente após os anos 1980 que estes termos passam a admitir a designação do comportamento internacional dos países, originando o conceito moderno de rogue states centrado no critério externo do comportamento estatal. Segundo o autor, este novo entendimento é inaugurado com a criação da "lista de Estados terroristas" pelo Departamento de Estado sob o Ato Administrativo de Exportação de $1979^{4}$ (LITWAK, 2000, p. 53), tratando determinados países como Irã, Líbia, Coreia do Norte, Cuba e Nicarágua como Estados que apoiariam o terrorismo internacional. Além disso, a busca por obtenção de armas de destruição em massa consistirá em um outro critério para o conceito de rogue; no entanto, Litwak ressalta que será somente no final da Guerra Fria que este critério se apresenta relevante. O terceiro critério relevante do conceito é o desprezo pelas normas internacionais.

Em termos de evolução do conceito e política de rogue state, os anos de 1980 foram um período de formação crucial os quais testemunharam a emergência dos critérios centrais, baseado no comportamento externo, que posteriormente viria a definir o que a Administração Clinton caracterizou como uma categoria de Estado. (LIWAK, 2000, p. 56)

\footnotetext{
${ }^{4}$ O Ato Administrativo de Exportação de 1979 (Export Administration Act - EAA) forneceu autoridade legal ao Presidente para controlar as exportações americanas em razão da segurança nacional, política externa, e/ou baixo suprimento.
} 
Assim, o termo rogue state serviria para designar países relacionados com um comportamento hostil internacionalmente, diretamente ligado a três critérios: a) a busca pelo desenvolvimento e obtenção de armas de destruição em massa; b) o uso de terrorismo internacional como instrumento de política estatal; c) comportamento hostil, colocando-se como ameaça regional ou global e/ou para os interesses americanos (LITWAK, 2000, p. 49).

Em concordância com Litwak, Martin Senn discute que o surgimento da ideia do conceito de rogues localiza-se na década de 1970, porém com a utilização de outros termos. Em seu livro Wolves in the Woods, o autor analisa os termos "rogue", "outlaw", "renegade", “(states) of concern", "pariah", e "axis of evil" e indica-os como "termos sinônimos para referirse a noção expressada pelo rótulo de rogue states (SENN, 2008, p. 31-32). A presente pesquisa, no entanto, se focará no termo específico rogue, embora a construção do conceito perpasse o uso dos outros termos sendo relevante sua apresentação.

A Doutrina de Rogue States assumida pelo governo Clinton mostra que os esforços militares deveriam ser concentrados em um número pequeno de países hostis como Coréia do Norte, Iraque e Irã, como pôde ser visto na declaração de Lake. A estabilidade de uma estrutura global bipolar encontrada na Guerra Fria já não existia mais, e segundo tal doutrina, o vácuo deixado pelo desaparecimento da URSS, abriria espaço para um sistema incerto e potencialmente mais perigoso, onde Estados agressivos pudessem agir e adquirir armas ofensivas de destruição em massa com maior facilidade. Dessa forma, os Estados Unidos deveriam estar aptos a se defenderem de possíveis ataques com armas de destruição em massa e tecnologias de mísseis balísticos. Acima de tudo, de acordo com Ivan Eland (ELAND; LEE, 2001, p. 3), a Doutrina de Rogue State é baseada na suposição que tais países agem irracionalmente e portanto possuem comportamento imprevisível.

Esta política foi desenvolvida posteriormente pela então Secretária de Estado Madeleine Albright em Setembro de 1997, ao se dirigir ao Conselho de Relações Exteriores. Ela afirma serem os rogue states e lidar com eles o "maior desafio de nossos tempos, (...) pois eles estão aí com o único propósito de destruir o sistema". Albrigth define ainda que os rogues states constituem uma das quatro diferentes categorias de Estados existentes no Sistema Internacional, anteriormente mencionado; as outras categorias de Estados seriam aqueles países de industrialização avançada, as democracias emergentes e por fim os Estados Falidos. 
O primeiro grupo é o maior, e composto por países que entendem as regras e as seguem - as regras do sistema internacional- para obter valor do fato de que eles são parte de um regime, e que há maneiras de proteger seu território, seu povo, e seu modo de vida. Agora, nós não concordamos com tudo o que seus governos fazem, mas nós concordamos na maior parte que deva existir algumas regras internacionais. O segundo grupo é o que eu denomino países em transição- aqueles que fizeram parte de impérios e que não possuem toda a estrutura a fim de fazer parte deste primeiro grupo, mas que gostariam de estar lá. O terceiro grupo são os rogue states - aqueles que não somente não fazem parte do sistema internacional, mas cujo próprio ser envolve estar fora dele e jogar, literalmente, granadas de mão dentro deste, a fim de destruí-lo. E por fim há, basicamente, os casos perdidos - países que não possuem estrutura qualquer, que não podem participar de forma alguma. (ALBRIGHT apud SENN, 2008, p. 14)

De acordo com Litwak, a política de rogue state foi essencialmente uma política de mobilização estratégica que consolidou uma gama de países e os demonizou sob um único rótulo. Esta política reflete a maneira maniqueísta da cultura política americana em ver as relações internacionais como uma luta moral entre as forças do Bem e do Mal.

As análises instrumentais do conceito de rogue state apresentadas por Paul Hoyt (2000), Kelly P.O’Reilly (2007) e Martin Senn (2008), em trabalhos distintos, demonstram a utilização de tal termo em discursos oficiais do Governo e da diplomacia americana.

Em seu trabalho, Hoyt (2000) procura entender a relevância política do termo rogue, quais países seriam assim denominados e quais ações ou comportamentos seriam específicos para denominar um Estado como rogue. Focando principalmente a Administração Clinton,

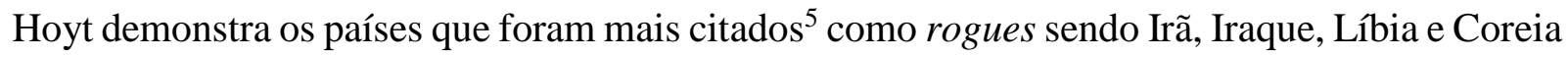
do Norte. O’Reilly (2007), conduzindo uma pesquisa com metodologia semelhante, porém abrangendo um período maior (1993-2004), alcança o mesmo resultado nas análises em relação aos países denominados rogues. Senn (2008), por sua vez, estende a pesquisa (porém analisando também termos correlatos, como pariah, outlaw, axis of evil, como mencionado acima) para o Governo Bush.

Os autores alcançam resultados semelhantes, revelando os comportamentos mais recorrentes associados aos rogues, em grande parte comportamento externo:

a. busca/posse/proliferação por armas de destruição em massa,

\footnotetext{
${ }^{5}$ A pesquisa de Hoyt foi feita quantificando a recorrência do termo "rogue" em pronunciamentos públicos da Presidência, do Departamento de Estado, do Departamento de Defesa e da CIA. O'Reilly conduz a pesquisa sem levar em consideração os pronunciamentos da CIA.
} 

b. ameaça/subversão/agressão ao sistema internacional,
c. envolvimento com/apoio ao terrorismo,
d. rejeição às normas internacionais
e. ódio/aversão aos Estados Unidos
f. imprevisibilidade/irracionalidade/fracasso da dissuasão

Martin Senn (2008, p. 14) aponta que na percepção americana, esta combinação entre "radicalismo e tecnologia" fariam com que os rogue states se tornassem uma grande ameaça, porém uma ameaça de natureza diferente da então proveniente da URSS. Rogue states são vistos como sendo atores irracionais com comportamento imprevisível quando sob pressão e supostamente tomariam mais riscos, sendo que ADM poderiam, então, ser usadas como armas de ataque - e não para defesa - e consequentemente, estes países não poderiam obter esta tecnologia.

A Administração Obama em uma tentativa de dar novo foco à Política Externa Americana tem feito pouco uso do termo rogue, tirando do centro das atenções a abordagem maniqueísta do governo Bush em relação à política externa e o uso de ataques preemptivos como maneira de lidar com rogues. A retomada do programa nuclear pela Coreia do Norte, os recentes acontecimentos na Líbia e as ações militares dirigidas ao governo de Qadhafi demonstram que as ofensivas contra certos estados não foram deixadas de lado; no entanto, o novo governo evita a classificação inflexível de tais Estados.

Como podemos depreender, o conceito de rogue states assume diferentes perspectivas e significados. Eric Herring (2000, p. 188) e Senn (2008, p. 17) oferecem uma avaliação do debate acadêmico em relação ao termo rogue state, subdividindo-o entre "conservador", "liberal", "esquerdista" e "interpretativo". 6

A perspectiva conservadora enfatiza que o conceito é objetivo e aplicável às ameaças aos Estados Unidos e aos seus aliados, representando adequadamente o caráter demoníaco e ameaçador destes Estados. De acordo com Thomas H. Henriksen em "The Rise and Decline of Rogue States", a emergência de "rogue powers", países com comportamento "delinquente" não

\footnotetext{
${ }^{6}$ Em uma tradução literal livre das diferentes perspectivas em relação ao debate do conceito de rogue state. Herring propõe quatro perspectivas em seu artigo "Rogue Rage: can we prevent mass destruction?", são elas "conservative perspective, liberal perspective, left-wing perspective and interpretivist perspective".
} 
é um fenômeno recente, podendo ser observado através da história. No entanto, "sua reaparição no cenário internacional foi vista com grande surpresa nos círculos políticos posteriormente ao colapso soviético" (HENRIKSEN 2001, p. 349, tradução nossa). Para ele, durante o século XX, houve algumas manifestações de comportamento rogue, apesar de poucos autores reconhecerem isso. O Bolchevismo sob o ponto de vista de Henriksen configurou um desses poderes (2001, p. 352): a ascensão dos Bolchevistas ao poder através da Revolução de Outubro trouxe uma agenda doméstica radical e críticas contra o status quo internacional. A contraposição ao sistema Imperialista Ocidental - de colonização e exploração de países subdesenvolvidos da África, Ásia e America Latina - juntamente com um modelo econômico que se opunha ao Capitalismo dominante nos países ocidentais era, "com uma doutrina estridente revolucionária, (...) pouco provável que a URSS não provocasse oposição em Londres, Paris e Washington”; sofrendo isolamento por parte dos Estados Unidos por mais de uma década, quando do surgimento do Nazismo na Alemanha as relações diplomáticas foram reatadas com o Governo F. Delano Roosevelt.

Henriksen faz referência à brutalidade interna e externa dos rogues, argumentando ainda que suas conexões com o terrorismo e suas relações entre poderes rogues são intensas apesar das diferentes características dos regimes (SENN, 2008, p. 19).

Contudo para a perspectiva liberal, o conceito possui um cunho subjetivo e exagera a natureza da ameaça sendo uma consequência da instrumentalização do conceito. Martin Senn (2008, p. 17) enfatiza que, apesar da diferença entre a definição conservadora e liberal, ambas assumem que os rogue states conferem uma ameaça aos interesses americanos. Enfatizam a subjetividade na rotulação dos países como rogue, além de argumentarem que tal categorização demoniza os mesmo e restringe as opções políticas americanas para com eles.

As explicações da perspectiva de esquerda (left-wing) ressaltam que a rotulação pode também ser aplicada aos Estados Unidos e a alguns dos seus aliados pelo comportamento agressivo e por ignorar princípios e normas internacionais como a intervenção militar não autorizada e os direitos humanos. O trabalho de Blum (2006) examina e critica a condução da política externa dos Estados Unidos durante e depois da Guerra Fria, destacando passagens nas quais a política externa americana violou princípios e condutas internacionais e qualificando o país como um rogue state. Da mesma forma, Noam Chomsky aponta o comportamento 
internacional americano como sendo agressivo a ponto de considerá-los um "rogue superpower".

A última perspectiva demonstrada foca sua análise principalmente em estruturas ideacionais, ou seja, valores e identidades. Com uma abordagem sobre a percepção dos chamados rogues no cenário internacional, a perspectiva "interpretativa" procura analisar através das interações entre dois atores (ego e alter), a construção da imagem que eles produzem e assumem deles próprios, em uma coconstituição. Um resumo destas quatro perspectivas pode ser visto na tabela 1.

Este trabalho procura seguir a linha desta última perspectiva, de forma a compreender o uso do termo rogue state pela política americana através da sua percepção do Outro.

Tabela 1. Conceito de Rogue States (baseado em E. Herring e M. Senn)

\begin{tabular}{|c|c|c|c|c|}
\hline & Conservadora & Liberal & Esquerdista & Interpretativa \\
\hline O conceito de rogue state... & $\begin{array}{l}\text { é uma } \\
\text { classificação } \\
\text { objetiva, } \\
\text { representando a } \\
\text { ameaça provinda } \\
\text { dos estados } \\
\text { cunhados como } \\
\text { tal }\end{array}$ & $\begin{array}{l}\text { é uma classificação subjetiva e } \\
\text { exagerada da ameaça. }\end{array}$ & $\begin{array}{l}\text { é também ap licável aos } \\
\text { EUA e países ocidentais, } \\
\text { em concordância com o } \\
\text { comportamento agressivo } \\
\text { no sistema internacional }\end{array}$ & $\begin{array}{l}\text { é imagem percebida } \\
\text { na co-constituição. }\end{array}$ \\
\hline \multirow[t]{4}{*}{ Alguns autores } & Henriksen (2001) & Caprioli,Trumbore (2005) & $\begin{array}{l}\text { Blum (2006) } \\
\text { Chomsky (2000) }\end{array}$ & $\begin{array}{l}\text { Herring }(2000) \\
\text { Senn }(2008)\end{array}$ \\
\hline & & Hoyt (2000) & & \\
\hline & & Litwak $(2000,2001)$ & & \\
\hline & & $\begin{array}{l}\text { Klare (1995) } \\
\text { O’Reilly (2007) }\end{array}$ & & \\
\hline
\end{tabular}

Fonte: Definições baseados em argumentação de E. Herring em “Rogue Rage: Can we prevent mass destruction?” 


\section{Percepções dos Rogue States: Construtivismo como base teórica}

Esta seção do artigo pretende apresentar a perspectiva Construtivista das Teorias de Relações Internacionais, que nos servirá de base para posterior análise da rotulação Rogue State pelos Estados Unidos a certos países, como mencionado anteriormente.

As teorias construtivistas ganham novos adeptos como nova perspectiva de estudo das Relações Internacionais durante os anos 1990. Trazendo a influência das teorias sociais, o construtivismo coloca em debate a relação entre agente e estrutura, sendo a principal crítica em relação às teorias positivistas. Agente e estruturas seriam codeterminados uns pelos outros, sendo construídos e modificados pela interação entre eles. Assim, o mundo não seria predeterminado, mas construído à medida em que os atores interagissem através do processo de comunicação transformando o mundo e a realidade em uma construção social. Apesar de algumas premissas básicas permearem todos os estudos construtivistas, podemos observar a pluralidade de "construtivismos" que há nos estudos de Relações Internacionais, cada qual apresentando uma particularidade em sua versão.

Apesar de não descartarem as causas materiais, os construtivistas consideram que as ideias e valores produzem significado à matéria, informando a relação entre o agente e o mundo, por sua vez proporcionando o conhecimento do próprio mundo. A realidade somente faria sentido se agregado algum valor ou informação sobre ela, isto é, "as pessoas agem em relação aos objetos, incluindo outros atores, baseado nos significados que estes objetos possuem para elas" (WENDT, 1995, p. 396, tradução nossa). Ao atribuirmos significado à matéria, mostramos que não há autonomia da mesma, senão a percepção sobre ela (ONUF, 1989, cap.1). Além disso, o Construtivismo desloca o debate para a antecedência ontológica dos agentes e da estrutura. As escolas positivistas tem como pressuposto a existência prévia da estrutura sendo anterior aos agentes; para estes, a estrutura independeria das ações dos agentes e não seria modificada por estes últimos; porém, limitaria e constrangeria a atuação dos mesmos. Para o construtivismo, no entanto, agentes e estruturas são elementos coconstitutivos e mutuamente dependentes de sua constituição e alteração. Consequentemente, os interesses e as preferências dos atores são construtos sociais decorrentes do contexto intersubjetivo e da interação agente-estrutura; os 
interesses são endógenos aos processos sociais e não predeterminados pela estrutura- mesmo se tratando de preferências em âmbito internacional.

Como mencionado anteriormente, observa-se uma grande variedade de teorias construtivistas, apesar de apresentarem premissas básicas entre si. Os estudos de dois autores contribuíram de maneira significativa para o desenvolvimento do construtivismo. Com grande influência de estudos linguísticos, Friedrich Kratochwil e Nicholas Onuf são os principais autores da "virada linguística" nas Relações Internacionais. Os autores irão propor que o "ato da fala" é um instrumento crucial para análise da política internacional. É no discurso - e principalmente nas regras que compõe este discurso- que estão contidas as intenções e interesses dos agentes, permitindo a compreensão da realidade. Assim, entender as regras e o discurso de fato é compreender o mundo ao qual nos referimos, pois este é o resultado dos próprios discursos em si; a realidade como ela é não nos importa, uma vez que nós somente compreendemos a realidade através da linguagem com a qual nos referimos a ela.

(...) atos de fala são constituídos por normas, isto é, eles se adéquam precisamente ao modelo de fato institucional (...). Só dentro de um determinado contexto regido por regras institucionais terá certa expressão um significado. Finalmente, nós podemos mostrar que é através de cada arranjo institucional que nós, como membros da sociedade, constantemente construímos a ponte entre o 'é' e o 'dever'. (KATROCHWIL, 1989, p. 31, tradução nossa)

Assim, para Kratochwil a linguagem não somente reflete a ação, mas é a própria ação em si. As normas constitutivas do discurso regem e organizam a tomada de decisão dos agentes, reduzindo a complexidade dos contextos nos quais as escolhas são feitas. Portanto, os atores tendem a voltar-se para as normas como forma de melhor depreender o conhecimento dos fatos e possibilitar sua tomada de decisão.

Normas são atos de fala, e elas dependem de uma comunicação bem sucedida (Kratochwil, 1989). Assim elas somente funcionam adequadamente se $\mathrm{o}$ ato de fala produzir o efeito desejado ao destinatário. Elas não são independentes da situação circunjacente. Se elas produzem o resultado desejado, elas ligam "autonomia individual a sociabilidade" fornecendo orientação e agindo como um dispositivo de resolução de problemas. (ZEHFUSS, 2001, p. 66, tradução nossa) 
Ao mesmo tempo, Kratochwil afirma que as normas não são somente instrumentos de ordenação do pensamento e da tomada de decisão, mas também podem funcionar como legitimadores de tais atos e decisões. Por serem produtos da construção social, as normas que regem o discurso podem influenciar e possibilitar certas ações como corretas e impossibilitar outras. Por isso para o autor, faz-se necessário a análise do discurso mediante o qual essas decisões foram tomadas para podermos compreender melhor o mundo e a realidade que nos cerca. Ainda, o autor expõe que

o discurso e a argumentação constituintes da prática social revelam [um] quadro de significados (cultura) em que se sustentam as escolhas dos atores políticos. Apesar de se tratar de um sistema compartilhado de significados, fundamental para a interação dos agentes sociais, isso não implica consenso. 'Afinal, por meio da sua presumida intersubjetividade, a linguagem' consiste justamente no lugar "onde os significados podem ser contestados e os conflitos surgem". No domínio da linguagem, confrontam-se não somente diferentes questões substantivas relacionadas a concepções, mas critérios para o próprio uso do termo. (BARROSO, 2010, p. 37)

Em conformidade com Kratochwil, Onuf considera as regras como elemento central no processo cognitivo entre agente-estrutura. Segundo o autor as regras definiriam padrões de conduta a serem seguidos, podendo ser acatados ou não, e fazendo dos indivíduos agentes neste processo social.

A coconstituição entre as pessoas como seres sociais e a sociedade é um processo contínuo. As regras são centrais para esse processo porque elas fazem das pessoas participantes ativos (ou agentes) em uma sociedade e dão a qualquer sociedade seu caráter distintivo (ou estrutura). As regras definem os agentes segundo as estruturas e as estruturas segundo os agentes... Conforme as regras mudam em numero, tipo, relação e conteúdo, elas redefinem agentes e estruturas, sempre um em relação ao outro. (GOULD, 1998, p. 80, tradução nossa)

Segundo Onuf, essas regras derivam do próprio discurso do indivíduo - que passa a ser o agente - nomeado de "atos de fala "-speech acts. Falar seria a própria ação; os indivíduos usariam a linguagem tanto como meio de expressar e comunicar suas ações, como a ação em si (GOULD, 1998, p. 81). Assim, todas as regras são 'atos de fala', mas nem todo ato de fala converte-se em regra; isto porque, e Onuf cita Kratochwill, "a retórica depende da audiência" (ONUF, 1989, cap.2), como mencionado acima. O alcance que o ato de fala consegue depende de como os ouvintes respondem ao proposto pelo orador. A contínua repetição do discurso com 
geração do mesmo efeito pode ganhar grande relevância e tornar-se uma convenção, por todos os envolvidos acreditaram na significância do discurso (ONUF, 1998, p. 66).

Se, no entanto, oradores frequentemente repetem um ato de fala em particular com os mesmos efeitos gerais, todos envolvidos começam a acreditar que a repetição torna-se significativa. [...] Repetido constantemente, o mesmo velho discurso transforma-se em convenção quando todos passam a acreditar que as palavras em si, e não os oradores as pronunciando, são responsáveis pelo o que acontece. (ONUF, 1998, p. 66, tradução nossa)

Convenções, no entanto, somente se tornariam regras a partir do momento em que os atores percebem e consideram que devam agir de tal forma, e não somente por ser sido feito desta forma sempre. Segundo Onuf, há três tipos de discurso (ou atos de fala) que dão origem a três regras correspondente: discurso assertivo, discurso diretivo e discurso de compromisso.

O discurso assertivo afirma uma crença ou opinião, ligada à intenção do orador de que o ouvinte irá aceitar tal opinião. Normalmente, o discurso assertivo informa os atores sobre como o mundo funciona e como as coisas são. Esse discurso pode produzir tanto princípios com informações apresentadas em termos gerais, quanto "regras de instruções" com informações em termos mais específicos, mostrando o que os indivíduos devem fazer com tais informações. Da mesma forma, o discurso diretivo oferece ao ouvinte a intenção do orador de como ele gostaria que uma ação fosse realizada. No entanto, este discurso é reconhecido por ser imperativo: o locutor afirma que o ator tem a obrigatoriedade de fazer tal ação. Deste discurso derivam as regras diretivas, informando não somente o que deveria ser feito, mas também as consequências de não seguir tais instruções. Por fim, o último discurso, o de comprometimento, promove a intenção do locutor em estar comprometido com uma situação em curso. Envolve necessariamente em promessas e ofertas. Ambas necessitam da aceitação do ouvinte para que se tenha efeito, como dito anteriormente; uma vez que tais promessas tenham alcançado generalização suficiente, elas se tornam regras de comprometimento. $\mathrm{O}$ autor destaca que ambos "os discursos diretivo e de compromisso tem a intenção de produzir o mesmo efeito, que é fazer com que o sujeito perlocucionário faça algo", embora, os discursos difiram "na identidade d[este] sujeito- outra pessoa ou si mesmo- e, desta forma, no locus da obrigação" (ONUF, 1998, p. 67-68, tradução nossa; ONUF, 1989, Cap. 2). 
Neste sentido, as regras oferecem aos atores escolhas simples para sua atuação - o ator pode escolher seguir a regra ou escolher quebrá-la. Ambas as opções produzirão consequências que são fáceis de serem estipuladas. Assim, escolhas racionais, segundo o autor, se tronariam mais fáceis de serem tomadas ao "declarar aos agentes aos quais eles se referem o que eles deveriam fazer em um tipo de situação que eles se encontrariam" (ONUF, 1998, p. 65, tradução nossa).

Enquanto consequências não intencionais são sempre possíveis, regras dão aos agentes a oportunidade de fazer escolhas racionais- escolhas ditadas por referência aos objetivos- com alguma segurança de que eles estão fazendo a melhor escolha disponível para si próprios. [...] Estes agentes podem agir no conteúdo da regra sem perceber que este conteúdo forma uma regra. Em princípio, no entanto, qualquer agente (incluindo qualquer observador com informação suficiente) pode formular conteúdos de regras. [...]O ato de falar na forma em que faça alguém agir é comumente chamado "ato de fala". (ONUF, 1998, p. 65-66, tradução nossa)

\section{A imagem do Rogue State na Política Externa Americana}

Ao analisarmos os discursos oficiais do governo americano em relação ao rogue states e nos quais há uma demonstração de como lidar com essa "nova ameaça", nos deparamos com uma política que se enquadra na classificação de "princípios" e "regras de instrução", segundo categorização de Onuf, enquanto regras e discursos. Por vezes, o discurso se torna mais incisivo, podendo produzir regras de comprometimento, ao utilizar verbos em que os Estados Unidos se comprometem a lidar com tais estados de maneira específica, como veremos adiante.

O discurso do presidente Ronald Reagan na 36॰ Conferência em Tóquio, Japão, em maio de 1986, foi o primeiro discurso oficial americano em que o termo rogue é mencionado para designar um país. A Líbia do Coronel Muammar el-Qaddafi foi vista como uma ameaça aos interesses americanos e ocidentais. A retórica americana vista neste discurso conecta o regime de Qaddafi com o apoio ao terrorismo internacional; podendo perceber a mudança no conteúdo das características do conceito de rogue state, como mencionado anteriormente. Há uma alteração no entendimento da ideia do termo, passando a designar o comportamento internacional dos países.

A Sétima reunião acordou sobre a ameaça representada pelo flagelo do terrorismo internacional e sobre novas medidas políticas e diplomáticas em lidar com o mesmo. Nós concordamos que a Líbia do Coronel Qaddafi representa uma ameaça única a 
liberdade das pessoas, um regime rogue que avança seus objetivos através de assassinatos e mutilação a civis inocentes. (REAGAN,1986, tradução nossa, itálico adicionado)

Este discurso refere-se ao ataque terrorista acontecido em uma discoteca em Berlin frequentada por oficiais militares americanos. Alegando ter interceptado mensagens de rádio da Embaixada da Líbia em Berlim que confirmassem o apoio do Cel. Qaddafi nos atentados, Washington, em abril de 1986, ordenou o bombardeio a cidades de Tripoli e Benghazi na Líbia em retaliação ao acontecido, justificado como autodefesa. O presidente Reagan em um pronunciamento horas após os atentados afirmou que "quando nossos cidadãos são atacados ou violados em qualquer lugar no mundo sob ordem direta de regimes hostis, nos iremos responder [a isso] enquanto eu estiver nesta função" (BBC 1986, tradução nossa). No entanto, a Líbia negou seu envolvimento e cumplicidade nos ataques (SCHMEMANN, 1988).

O fim da Guerra Fria seguida pela eclosão da Guerra do Golfo I aprofundaram a percepção americana negativa em relação a determinados Estados do Terceiro Mundo. Apesar das relações entre Estados Unidos e Iraque não apresentarem tanta hostilidade na década de 1980, o Iraque se tornaria o rogue state "arquetípico" (LITWAK, 2000, p. 55) do pós-Guerra Fria.

Ainda que nos Governos de Reagan e Bush o termo rogue state não tenha sido utilizado como política oficial, nota-se a construção do conceito através das interações entre os Estados Unidos e os países denominados por este último como outlaw, mais tarde rogues. Através do processo cognitivo, o decisionmaker estrutura o ambiente ao seu redor, construindo através da percepção do Outro, o seu próprio entendimento do Outro.

A análise dos discursos nos revela essa interação e nos ajuda a entender a percepção dos atores, pois é no "ato de fala" que está contido as intenções dos atores e as ações em si. Os discursos de Saddam Hussein e seu Conselho e de Bush sobre as invasões do Kuwait e a iminência da Guerra do Golfo nos mostra a percepção destes países como inimigos. O Ministro da Defesa do Iraque repetidas vezes refere-se aos Estados Unidos ou a figura do Presidente Bush como inimigo ${ }^{7}$ :

\footnotetext{
${ }^{7}$ Transcrição de uma reunião entre Saddam Hussein e Conselho do Comando Revolucionário, em 29 de Dezembro
} 
Saddam: Os Kuwaitianos, eles estão certos que o ataque acontecerá no dia 15, certo?

Ali Hassan Majid: Sim, Senhor, eles estão certos, e eu falei aos nosso irmãos, quanto mais trabalharmos nossa prontidão maiores serão as chances sobre o inimigo, e talvez a guerra será atrasada. Quando ele [Bush] ver quão preparado nós estamos e como ele não pode invadir a cidade - [interrupção]

Saddam: Sim, está correto, é por isso que a guerra está atrasada até agora.

Ali Hassan Majid: Porque nosso inimigo tem seu olho e está olhando de dentro do Kuwait, com certeza. O inimigo tem inúmeros olhos dentro da cidade de al-Kazma que relata tudo a ele diretamente. Nós pretendemos enviar nossa mensagem diretamente ao inimigo. Honestamente, nós observamos e vemos tudo que acontece. Nosso trabalho é claro, e talvez ninguém do mundo árabe acredita que podemos resistir a América; portanto, o povo Kuwaitiano tem a impressão que a América é seu salvador. Então, não somente são tolos, mas estão com medo. [...]. Graças a Deus. Mais uma vez, nossa prontidão é grandiosa e [não há] nada que precisamos. (CRRC, 1990, p. 2-3; tradução nossa, itálico adicionado)

Ao mesmo tempo, a Administração Bush coloca as ações de Saddam Hussein como sendo próprias de um outlaw. Muitos analistas indicam que dentre as várias razões para os Estados Unidos irem para a guerra, a preocupação com um Iraque nuclearmente armado foi a principal.

A agressão do Iraque causou sofrimento, dificuldade e incerteza. [...] Nos 5 meses seguintes a 2 de Agosto [1990], o mundo testemunhou a emergência de uma coalizão sem precedentes contra a agressão. Nas Nações Unidas, os atos outlaw do Iraque recebeu um coro de condenação em 12 resoluções com o apoio esmagador do Conselho de Segurança. [...] Saddam pode procurar separar a coalizão, explorar nosso sincero desejo pela paz, para assegurar a si próprio os despojos da guerra. [...] O próximo conflito vai encontrá-lo ainda mais forte - talvez mesmo na posse de armas nucleares - e muito mais difícil de derrotar. E isto é a razão de nós simplesmente não aceitarmos nada menos que a observância plena do que a ONU dita: retirada completa e incondicional iraquiana do Kuwait. (BUSH, 1991a, tradução nossa, itálico adicionado)

Em outro importante discurso durante a Assembleia Geral da ONU em setembro de 1991:

Um ano atrás, a União Soviética juntou-se aos Estados Unidos e uma série de outras nações para defender um pequeno país contra agressão e opondo-se a Saddam Hussein. Pela primeira vez em um assunto de grande importância, a competição entre as superpotências foi substituída pela cooperação internacional. As Nações Unidas, em um dos seus melhores momentos, construiu uma resposta calculada, baseada em princípios, deliberada e corajosa a Saddam Hussein. Ela se

de 1990. Em: http://crrc.dodlive.mil/files/2013/06/SH-SHTP-A-001-042.pdf "Saddam Hussein and the Revolutionary Command Council Discussing the Iraqi Invasion of Kuwait and the Expected U.S. Attack" 
impôs a um outlaw que invadiu o Kuwait que ameaçou muitos Estados da região que procurou estabelecer um precedente ameaçador para o mundo pós-Guerra Fria. Os esforços da coalizão estabeleceram um modelo para a solução coletiva de disputas. Os membros estabeleceram o objetivo, a liberação do Kuwait, e concebeu um meio corajoso e unificado de alcançar esse objetivo (BUSH, 1991b, tradução nossa, itálico adicionado).

A Administração Clinton assume, oficialmente, os Rogue States como sendo uma das ameaças à Segurança Internacional e consequentemente aos Estados Unidos na década de 1990. A preocupação em como lidar com a emergência e a ação de tais Estados levou a constituição da estratégia de segurança nacional de 1994 e 1995, voltada para os perigos emanados dos rogue states, apresentado na "National Security Strategy of Engagement and Enlargement" (NSS, 1995).

A expansão da ameaca rogue é abordada logo no prefácio da estratégia NSS1995: “O fim da Guerra Fria mudou fundamentalmente os imperativos da segurança da América. [...] e os rogue states representam um sério perigo a estabilidade regional em muitos lugares do globo. A proliferação de armas de destruição em massa representa um grande desafio a nossa segurança” (NSS, 1995, prefácio, tradução nossa).

Ela é baseada na expansão da comunidade de democracias de mercado ao mesmo tempo em que pretende dissuadir e conter ameaças à nação americana, a seus aliados e a seus interesses. Os três componentes centrais da estratégia de "Engagement \& Enlargement" seriam: os esforços para aumentar a segurança através da manutenção de fortes capacidades de defesa e da promoção de medidas de cooperação de segurança; o trabalho para abrir mercados estrangeiros e estimular o crescimento econômico global; e a promoção da democracia.

No entanto, a estratégia elaborada pelos EUA para lidar com os dois principais países que confeririam a maior ameaça parte da política apresentada por Anthony Lake. Em seu artigo que permanece como a mais detalhada articulação da política dos Rogue States da Administração Clinton, ele (LAKE, 1994) propõe a contenção dupla - dual containmentdirigida ao Irã e ao Iraque, as duas maiores apreensões dos EUA, apesar da menção de outros países como membros do grupo dos Rogues (ou os Estados "backlashs") como Líbia e Coreia do Norte. 
Nossa política deve enfrentar a realidade de Estados rebeldes e outlaw que não somente escolheram permanecer fora da família [das nações] mas também violam seus valores básicos. Há alguns estados "backlash”: Cuba, Coreia do Norte, Irã, Iraque e Líbia. Por enquanto lhes faltam os recursos de superpotência que lhes permitiriam ameaçar seriamente a ordem democrática sendo criada ao seu redor. Contudo, seu comportamento é frequentemente agressivo e desafiador. Os laços entre eles estão crescendo enquanto eles procuram impedir ou por eles mesmo de quarentena de uma tendência global da qual eles parecem incapazes de se adaptar. (LAKE, 1994, p. 45, tradução nossa)

O foco nesses dois países resulta da premissa que estes dois regimes perseguiriam políticas hostis aos interesses americanos. A contenção da proliferação de armas nucleares e a necessidade de criar uma Balança de Poder favorável na região do Golfo Pérsico para a proteção dos interesses americanos e de seus aliados fazem com que os esforços sejam dirigidos a conter esses dois países. Martin Indyk, diretor sênior para as Relações do Oriente Médio e Sudeste Asiático já enunciara em 19 de Maio de 1993 no Conselho de Segurança Nacional no Instituto de Washington esta nova abordagem para com o Irã e Iraque, posteriormente aprofundada por Lake:

A política de "dual containment" do Irã e do Iraque da Administração Clinton deriva no primeiro momento de uma avaliação que os regimes iraquiano e iraniano atuais são ambos hostis aos interesses americanos na região. Desta forma, nós não aceitamos o argumento que nós devemos continuar o antigo jogo de balança de poder, fortalecendo um para balancear o outro. Nós rejeitamos essa perspectiva não somente porque sua falência foi demonstrada na invasão iraquiana no Kuwait. Nós a rejeitamos devido a uma avaliação clara do antagonismo que ambos regimes abrigam em relação aos Estados Unidos e seus aliados na região. E nós a rejeitamos, pois não precisamos nos apoiar em um para balancear o outro. (INDYK, 1993 apud LITWAK, 2000, p. 59, tradução nossa)

Segundo Lake (1994, p. 46), o governo Clinton enfrenta este desafio com vantagens que os últimos governos não possuíam: a busca por uma balança de poder favorável mostra-se sem a necessidade de depender do Iraque ou do Irã; ao invés de haver um apoio americano a uma nação para contrapor a outra, Washington buscaria manter sob controle ambos os países. Algumas mudanças no cenário internacional contribuíram para isso: o fim da Guerra Fria eliminou a preocupação com a estratégia soviética de apoio a um dos dois países do Golfo Pérsico em posição ao apoio americano ao outro país, (BOYS, 2005) "não mais o inimigo (Iraque) do inimigo (Irã) dos Estados Unidos seria amigo deste último"; a redução da capacidade militar de ambos os países após a Guerra Irã-Iraque e após a Operação “Tempestade do Deserto 
I" (Desert Storm de 1991); o apoio do Conselho de Cooperação do Golfo (Gulf Cooperation Council) às ações de Washington; e relações favoráveis com países da região como exemplo, Egito, Israel, Turquia e Arábia Saudita.

Lake explicita que o objetivo básico dessa estratégia era conter as hostilidades vindas de Teerã e Bagdá, no entanto com diferentes abordagens, pois os dois regimes apresentavam desafios distintos. Após a publicação de Lake no periódico Foreign Affairs, o termo foi largamente utilizado pelos oficiais do governo Clinton, inclusive o presidente. De acordo com Litwak, o governo Clinton utilizou a rubrica rogue ao descrever os desafios da segurança internacional contemporânea. Ainda Litwak revela que o termo serviu como base para uma mobilização externa e interna em relação a assuntos relacionados ao controle de armamentos.

A administração invocou o termo para mobilizar o apoio domestico e internacional para maiores medidas multilaterais de controles de armamentos; isto forçadamente argumentou que a extensão da comunidade internacional do TNP em Maio de 1995 e a ratificação pelo Senado da Convenção de Armas Químicas em abril de 1997 iria reforçar as normas internacionais contra a proliferação e dificultar de maneira prática para os rogues states a aquisição de armas de destruição em massa devido aos regimes de controle de exportação de tais tratados. [...] Estes exemplos refletem a aceitação crescente da rubrica rogue state como um termo de referencia no debate da política Americana. (LITWAK, 2000, p. 64, tradução nossa)

As ações tomadas pelos EUA para com esses países ficavam no campo de sanções econômicas e isolamento diplomático pretendendo mantê-los fora das fronteiras "normais" da política internacional (SAUNDERS, 2006, p. 28). Um dos casos que nos mostra essa política é o Ato de Sanções Irã-Líbia (Iran-Libya Sanctions Act-ILSA) de 1996, que impunha sanções econômicas a empresas que comercializavam com o Irã e Líbia, sendo este último um país também considerado como rogue. Este tipo de atitude americana promoveu o que E. Saunders chamou de "Desentendimento Transatlântico", ou seja, não sendo ações aceitas por muitos países da União Europeia, como a França que as criticou veementemente (SAUNDERS, 2006, 28, tradução nossa).

Em todo o mundo, as pessoas anseiam viver em paz. E esse sonho está se tornando uma realidade. Mas o nosso tempo não está livre de perigo. À medida que a guerra fria dá lugar à aldeia global, muitas pessoas continuam vulneráveis à pobreza, doença e subdesenvolvimento. E todos nós estamos expostos ao ódio étnico e religioso, a agressão irresponsável de rogue states, terrorismo, crime organizado, tráfico de drogas, a proliferação de armas de destruição em massa. O surgimento da era da tecnologia e da informação trouxe-nos mais juntos e nos deu oportunidades extraordinárias para construir um futuro melhor. Da mesma forma com que na 
nossa aldeia global, o progresso pode se espalhar rapidamente, o problema o pode, também. Problemas no extremo da cidade logo se tornam uma praga na casa de todos. Não podemos libertar as nossas próprias vizinhanças de criminalidade associada à droga, sem a ajuda de países onde as drogas são produzidas. Não podemos rastrear terroristas sem a ajuda de outros governos. Não podemos prosperar ou preservar o nosso meio ambiente, a menos que o desenvolvimento sustentável é uma realidade para todas as nações. E a nossa vigilância por si só não pode manter as armas nucleares armazenadas a meio mundo de distância de cair nas mãos erradas. (CLINTON, 1995, tradução nossa)

Ao mesmo tempo, a preocupação com a ameaça norte-coreana e iraniana em relação aos seus programas de mísseis balísticos de longo alcance promoveu uma corrida para o lançamento de um sistema americano de defesa contra mísseis: a National Missile Defense (NMD). Em 1999, foi assinado o ato para a criação de tal sistema, a National Missile Defense Act, pelo Presidente Clinton. Este envolvia o desenvolvimento de interceptadores de mísseis a partir do solo, utilizando radares e satélites capazes de guiá-los para destruir mísseis de longa-distância.

A partir da nota divulgada pelo governo norte-coreano, em junho de 1997, demonstrase um discurso incisivo em relação a seus adversários políticos. Esta postura contribui para assimilação por parte dos Estados Unidos de uma imagem odiosa de tal país.

O grupo fantoche sul-coreano está planejando introduzir 307 milhões de dólares em 1060 mísseis "stinger" e 200 lançadores dos Estados Unidos, de acordo com um relatório do rádio de Seul. Foi revelado pelo plano de venda de mísseis "stinger" da Coreia do Sul anunciado pelo Departamento de Defesa dos EUA. O grupo Kim Young Sam, abandonado pelo povo por sua política anti -social e de acumulação de fortuna, continuam a apresentar material de guerra em aliança com os elementos bélicos dos Estados Unidos em uma tentativa de buscar uma saída para suas manobras de provocação de guerra contra o Norte. (KCNA, 1997)

Ainda, em outro momento, em relação ao Japão e a manipulação de mísseis balísticos

O porta-voz do Comitê Coreano para a Paz da Ásia-Pacífico emitiu um comunicado hoje acusando o Japão de fazer uma confusão nestes dias sobre um teste de lançamento de mísseis de longa distância que o Japão diz ter sido conduzido pela Coreia do Norte. O porta-voz diz: "funcionários de alto escalão e outros políticos do Japão estão fazendo declarações provocativas contra a Coreia do Norte em relação a um teste de lançamento de mísseis que dizem ter sido realizado pela RPDC. Eles descrevem o teste como algo "lamentável " e " perigoso" e afirmam que o teste dificultou melhorarias nas relações com a Coreia do Norte. É imprudente para o Japão dizer isso ou aquilo, sem saber se a Coreia do Norte fez um teste de mísseis ou qualquer outra coisa. O comportamento do Japão é ridículo, na verdade, em vista do fato de que o Japão está zelosamente 
desenvolvendo instrumentos de lançamento de longa distância e outras armas e abrindo caminho para a agressão exterior, tendo realizado diretrizes para a cooperação em defesa Japão-EUA'. Muitos países ao redor do Japão possuem ou têm implantado mísseis. Políticos japoneses, no entanto, lançam lama apenas contra a Coreia do Norte, enquanto desconhecem os acontecimentos. Eles emanam da política hostil de longa data para com a Coreia do Norte. Japão tem até agora jogado um balde de água fria sobre a atitude magnânima do Partido dos Trabalhadores da Coreia e o governo da RPDC para o desenvolvimento de boas relações entre os dois países, por respondê-la com uma campanha anti-Coreia do Norte. Japão deve necessariamente pagar os 40 anos ímpares de sua ocupação da Coreia e assassinato de coreanos e pilhagem. Nós amargamente denunciamos o Japão por fazer um alarido sobre o assunto que pertence a nossa soberania, enquanto desconhecem os fatos. Advertimos o Japão para enfrentar a realidade, agir com discrição e renunciar à sua política hostil anacrônico para a Coreia do Norte de uma só vez. (KCNA, 1998, tradução nossa)

Deste contexto do surgimento e aplicação do termo rogue state na Política externa americana, depreendemos "dois momentos" dos discursos americanos em relação aos rogues, que por vezes são concomitantes. Os discursos assertivos, em que se pretende caracterizar o novo tipo de ameaça, dando forma e construindo a visão de um novo inimigo aos Estados Unidos - posteriormente inimigo global - e os discursos de comprometimento e engajamento em políticas, nem sempre tão bem definidas, em relação a estes mesmos países.

As Estratégicas de Segurança Nacional que se seguiram no governo Clinton mencionaram os rogue states como sendo ameaça aos Estados Unidos (NSS 1996, 1998, 2000), sendo somente nas NSSs de 1997 e 2001, dois momentos nos quais o termo rogue não foi utilizado (NSS1997, 2001) ${ }^{8}$.

A primeira estratégia de Segurança Nacional Americana pós-atentados de 11 de setembro, a NSS2002, enfatiza a segurança e a defesa da Nação perante estas novas ameaças que enfrentam os Estados Unidos. Os atentados fizeram crescer a preocupação com o terrorismo e atores que pudessem se aproveitar do aparato estatal de um Estado Falido para suas ações (NSS, 2002). A necessidade de se definir essa nova ameaça provinda, tanto de grupos terroristas e consequentemente os Estados dos quais estes podem se aproveitar e quanto dos rogue states,

\footnotetext{
${ }^{8}$ As datas das National Security Strategies são referentes ao ano para qual elas se dedicam e não a data de sua publicação. Fonte: nssarchive.us.
} 
se faz presente na apresentação da nova estratégia de segurança, como visto na citação do presidente Bush no início deste artigo.

Sob a alegação que os inimigos da Nação buscam abertamente conseguir meios de desenvolver armas de destruição em massa, a NSS2002 retoma a idéia do Programa Nacional de Defesa para contenção de mísseis já apresentado na Administração anterior, porém naquele momento sem muita aceitação dentro do governo. A estratégia para combater a proliferação de armas de destruiçao em massa, e consequientemente o uso delas por rivais passa pelos eforços pró-ativos de counterproliferation - deter e defender contra a ameaça antes que ela se materialize -, aumentar esforços para a não-proliferação impedindo a aquisição de materiais, tecnologias e expertise necessária para o desenvolimento de tais armas por grupos terroristas e países, e por fim um gerenciamento eficaz e efetivo para ser capaz de responder a um possivel uso de ADM por terroristas e países hostis.

O medo de um ataque contra os americanos utilizando armas de destruição em massa, principalmente nucleares, depois de terem vivenciado um ataque terrorista em Nova Iorque leva ao desenvolvimento de uma estratégia diferente da apresentada no governo anterior: a NSS do governo Clinton visava uma conteção utilizando-se do isolamento político e sanções como medida mais direta para lidar com os rogues states, além do engajamento seletivo e a democratização de tais Estados. Segundo Robert W. Merry (SIMON; SCHUSTER, 2005), a NSS2002, que ficou conhecida como Doutrina Bush, (PREBLE, 2005) propõe três linhas principais de atuação: a ação preemptiva, democratização e o domínio.

Essa nova estratégia coloca a ação preventiva como sendo uma das principais formas de combater a ameaça vinda desses atores, devendo a Nação americana “[...] estar preparada para deter rogue states e seus clientes terroristas antes que eles se tornem capazes de ameaçar e usar armas de destruição em massa contra os Estados Unidos, seus aliados e seus amigos" (NSS, 2002, tradução nossa). Pode-se entender por ação preemptiva o ataque ao inimigo antes que ele faça um primeiro ataque, a partir da existência de uma ameaça iminente. Apesar de ser considerada uma ação legítima por alguns juristas internacionais, ela apresenta muitos opositores. Para Preble, a ação preeemptiva do Governo Bush é melhor entendida como "guerra preventiva". 
A visão que o Governo Bush possui em relação aos rogue states aprofunda a ideia já apresentada de irracionalidade destes atores. Esta abordagem sugere que suas ações não podem ser previstas uma vez que não seguem a racionalidade dos demais atores do sistema internacional; seriam atores mais capazes a tomar riscos, a "apostar" com as possibildades de ação. Durante a NSS é apontado que o uso de armas nucleares é uma opção para eles como sendo um recurso para ataque, diferentemente da Guerra Fria em que as armas nucleares eram vistas como o último recurso para defesa.

Nossos inimigos veem Armas de Destruição em Massa como armas de escolha [para uso]. Para os rogue states, estas são armas de intimidação e agressão militar contra seus vizinhos. Estas armas podem também permitir estes Estados a tentar chantagear os EUA(...). (NSS, 2002, tradução nossa)

(...) quanto maior ameaça, maior é o risco de inação - e mais convincente [se torna] o caso de tomar uma ação antecipada para defender-nos, mesmo se incertezas permanecem como na hora e lugar que os inimigos atacarão. Para antecipar ou prevenir estes atos hostis de nossos adversários, os Estados Unidos irão, se necessário, agir de forma preemptiva. (NSS, 2002, tradução nossa)

Preble analiza ainda o aspecto coercitivo da Doutrina Bush como sendo uma forma de demonstrar o poder americano e desencorajar outros rogues, convencendo-os de abandonar seus regimes despóticos.

Igualmente importante é o efeito da demonstração que é esperado a estender aos outros regimes rogues: "Você quer que isto aconteça com você?' Com sua postura coercitiva, a política Americana objetiva convencer regimes despóticos a abandonar suas vias autocráticas, ou sofrer o mesmos destino de Saddam Hussein (PREBLE, 2005, tradução nossa)

A National Security Strategy de 2006 na segunda Administração Bush (2005-2008) somente vem reafirmar a Doutrina Bush: mais do que nunca a "guerra contra o terror" está na pauta da política externa americana. São "tempos de guerra"9 que os Estados Unidos vivem, travando uma batalha contra as ameaças terroristas emergentes.

A luta contra o terrorismo “(...) não terminou. A América está mais segura, mas ainda não está totalmente segura" (NSS, 2006, tradução nossa). Marcada pela insistência em ataques repentinos à segurança americana, a estratégia visa conter as redes de poder terroristas com

\footnotetext{
9 (NSS, 2006) "This is a wartime national security strategy (...).” Prefácio.
} 
medidas externas -como a ação no Afeganistão impactando diretamente a Al-Qaida- e internas, como o Patriot Act.

A NSS2010 já no Governo Obama não se refere a tais países como sendo rogues; há um abandono do termo por este governo, como forma de dar novo direcionamento à política externa americana. No entanto, o termo ainda é utilizado por autoridades de dentro do governo com o mesmo sentido, tendo em vista declarações da Secretária de Estado Hillary Clinton quando perguntada em entrevista sobre as maiores preocupações em relação às armas nucleares: “(...) A grande preocupação sempre quando você está em um a posição como esta é o medo de que possa haver proliferação nuclear e - ou por um rogue state ou por um ator não-estatal" (U.S. Department of State, 2012, tradução nossa).

\section{Considerações finais}

Em seu artigo "Is there such thing as a Rogue State?", Janna Thompson argumenta que a noção de rogue state é incerta, ou até mesmo incoerente. A autora desconstrói os argumentos que suportam a ideia de rogue state, reforçando que o uso desta rotulação a certos países pode encorajar outros membros da sociedade internacional a travarem guerras contra eles, os tornando por objetos justificáveis de ataques, invasões e reconstrução, uma vez que tal termo os coloca como ameaças ao sistema e não merecedores do respeito internacional (THOMPSON, 2002).

Muito críticos do termo o consideram analiticamente insustentável e extremamente subjetivo. Os critérios levantados por Litwak para designar um país como Rogue, não seriam utilizado objetivamente pela diplomacia americana.

O caso da Síria durante a Administração Clinton é emblemático. Pela sua importância política para os Estados Unidos, o governo de Damasco foi excluído da lista de rogues apesar de apresentar um comportamento internacional perturbante. Se tivesse o denominado como rogue, as aberturas políticas para com esse país, teriam sido muito mais difíceis (ou impossíveis), uma vez que a política usual a ser adotada seria a de contenção.

Levando em consideração a perspectiva construtivista, países como Irã, Iraque e Coréia do Norte perceberiam e seriam percebidos pelos Estados Unidos como sendo Estados de comportamento agressivo, principalmente destrutivo e ameaçadores de sua integridade e 
sobrevivência internacional. Esta identidade somente ganha sentido dentro do contexto intersubjetivo em questão.

Assim ao assumir os Rogues States como sendo uma das ameaças à segurança internacional e consequentemente aos Estados Unidos na década de 1990/2000, Administração Clinton/Bush preocupou-se em caracterizá-los e lidar com tais Estados através da constituição de estratégias de segurança nacional voltadas a eles (NSS, 1994, 1995, 1996, 1998, 2000, 2002, 2006). Como mencionado anteriormente, o uso de discursos e sua repetição possibilitaram a criação de "regras de instrução" e princípios como forma de tentar explicar o novo contexto em que os Estados Unidos se encontravam. No entanto, ao definí-los sob algumas caracteristicas e comportamentos, os policy makers não caracterizaram uma nova categoria de Estado como Madeleine Allbrigt assumia ser, mas abarca sob um único rótulo uma percepção americana sobre tais Estados. Hoyt ao analisar a lista de países intitulados rogue e os comportamentos relacionados a eles aponta que:

[...] rogues não constituem uma classe coerente de Estados, objetivamente determinados baseados em comportamento. A falta de correspondência entre as ações estatais e a lista dos rogue states indicam que um não é inteiramente determinante do outro. Esta falta de adequamento entre o rótulo e o comportamento pode ser reolvida pela adoção da perspectiva que rogues não são absolutamente uma categoria de Estado, mas eles são na verdade uma imagem perceptual, isto é, uma construção cognitiva utilizada pelos policy-makers para explicar o mundo a sua volta. O que o Irã, Iraque, Líbia e Coreia do Norte e outros partilham não é um conjunto uniforme de comportamentos delinquentes, mas uma percepcao comum pelos policy-makers americanos (HOYT, 2000, p. 307, tradução nossa).

Nota-se que uma vez considerado um rogue a política adotada pelos Estados Unidos difere da usual, mesmo considerando um outro país inimigo.

[d]erivado de um conjunto diferente de julgamentos, as escolhas estratégicas que seguem a adoção da imagem de rogue varia grandemente daquele de imagem de inimigo. Enquanto a imagem de inimigo desfruta de uma política de deterrence e contenção, a imagem rogue gera uma escolha estratégica que é muito mais constrangido. A percepção de cultura inferior dentro dos chamados rogue states diminui a fé em negociações estratégicas e em medidas de construção de confiança como meio para resolução de disputas com rogues. Mais ações agressivas são consideradas necessárias. Reforçando esta tendência, está uma assimetria de poder favorável, que torna menos necessário depender da diplomacia. Força é vista como apropriada e praticável. O resultado é a escolha estratégica que favorece comportamento de constrangimento por parte dos Estados Unidos. (HOYT, 2000, p. 309, tradução nossa) 
O uso da força é claramente visto na NSS2002, como demonstrado anteriormente. Guerra preemptiva, eliminação de regimes autoritários pela força formam o centro das políticas americanas para tais Estados. Outras formas pesadas de repressão em relação aos rogues foram as sanções políticas e econômicas (ex. Iran-Libya Sanctions Act, e apoio americano a sanções da ONU contra o Iraque), ações para enfraquecer a estabilidade política (através de, por exemplo, o Iraq Liberation Act, o Cuban Democracy Act, e dinheiro federal alocado para financiar esforços da oposição no Irã e no Iraque) e grande pressão para a adoção de certos acordos internacionais - notavelmente o Tratado de Proliferação Nuclear (HOYT, 2000, p. 309).

Notavelmente, adotar políticas mais ofensivas em relação aos rogues está diretamente ligada à percepção dos mesmos como possíveis atores irracionais e então, não passíveis de dissuasão. Da mesma forma, são percebidos como agressivos e revisionistas do status quo internacional, com grande tendência a aceitar mais riscos na tomada de decisão.

O termo rogue state, portanto, não é aplicado pelo governo americano de forma utilitária, senão, subjetivamente, a partir de sua percepção em relação aos outros Estados do Sistema Internacional (HOYT, 2000) conforme sua interação e construção no contexto intersubjetivo demarcado por discurso e regras que corroboram essa imagem. 


\section{REFERÊNCIAS}

ABRAHMS, Max “ When Rogues defy Reason: Bashar's Syria” Fall 2003 Meforum (Middle East Forum); In: http://www.meforum.org/562/when-rogues-defy-reason-bashars-syria.

ARMS CONTROL ASSOCIATION (ACA) 2013, Solving the Iranian Nuclear Puzzle. Disponível em: http://www.armscontrol.org/events/Iran-Nuclear-Puzzle-Briefing-Series

BARROSO, Juliana L. V. 2010. Análise do contexto intersubjetivo: A Política Diplomática de promoção da democracia dos Estados Unidos para a América Latina no pós-Guerra fria. Tese de Doutorado, Universidade de São Paulo

BBC 1986. US launches air strikes on Libya. 15 de Abril. Disponível em:

http://news.bbc.co.uk/onthisday/hi/dates/stories/april/15/newsid_3975000/3975455.stm

BLEIKER, Roland 2003. A rogue is a rogue is a rogue. US foreign policy and the Korean nuclear crisis, International Affairs 79,v. 4, 719-737.

BLUM, William. 2002 Rogue State. A Guide to the World's Only Superpower. Zed Books. London et al.

BOYS, J. D. 2005. The dual containment of rogue states. Nth Position Website.

BUSH 1991a. Message to Allied Nations on the Persian Gulf Crisis. 8 de Janeiro. Disponível em:http://bushlibrary.tamu.edu/research/public_papers.php?id=2598\&year=1991\&month=01

1991b. Address to the 46th Session of the United Nations General Assembly in New

York City. 23 de Setembro. Disponível em:

http://bushlibrary.tamu.edu/research/public_papers.php?id=3415\&year=1991\&month=09

CHOMSKY, N. 2000. Rogue States: The Rule of Force in World Affairs. South End Press. Cambridge, MA.

CLINTON 1995. Address by President Bill Clinton to the UN General Assembly. 22 de Outubro. Disponível em: http://www.state.gov/p/io/potusunga/207409.htm

CRRC 1990. "Saddam Hussein and the Revolutionary Command Council Discussing the Iraqi Invasion of Kuwait and the Expected U.S. Attack". CRRC Record Number: SH-SHTP-A-001042. Disponível em: http://crrc.dodlive.mil/files/2013/06/SH-SHTP-A-001-042.pdf

ELAND, I., \& LEE, D. (9 de March de 2001). The Rogue State Doctrine and National Missile Defense. Cato Institute-Foreign Policy Briefing , 13.

HENRIKSEN, T. H. (Spring de 2001). The Rise and Decline of Rogue States. Journal of International Affairs, pp. 349-371.

HERRING,E. (2000) “Rogue Rage: Can we prevent mass destruction?”Journal of Strategic Studies, 23, n॰1, p.184-212.

HOYT, Paul D. 2000. The "Rogue State" Image in American Foreign Policy. Global Society 14 (2). 
KCNA 1997. South Korean puppets to introduce stinger missiles. 12 de Junho. Disponível em: http://www.kcna.co.jp/index-e.htm

1998 Japan warned to act with prudence. 02 de Setembro. Disponível em: http://www.kcna.co.jp/index-e.htm

KLARE, M. (1995) Rogue State and Nuclear outlaws: America's search for a new foreign policy. Hill and Wang, New York.

KRATOCHWIL, Friedrich V. (1989) "Constructivism as an approach to Interdisciplinary Study” in FIERKE, Karin M. \& JORGENSEN, Knud Erik (ed.) Constructing International Relations: the next generation (2001) New York

LITWAK, R. ( 2000) Rogue States and U.S. Foreign Policy:Containment After the Cold War. Woodrow Wilson International Center for Scholars. Washington, D.C.

(2001). What is in a name? The Changing Foreign Policy Lexicon. Journal of International Affairs, pp. 375-392.

LAKE, A. (1994). Confronting Backlash States. Foreign Affairs. Vol.73 No.2 (March/April), pp.45-55

MISLAN, D. B. (2007). Reality, not Rhetoric:The Rogue State label in American Foreign Policy. International Studies Association (Annual Meeting). Chicago,Illinois

NSSUSA (1994) National Security Strategy of United States of America. Washington DC: Government Printing Office.The White House.

(1995) National Security Strategy of United States of America. Washington DC: Government Printing Office. The White House.

(1996) National Security Strategy of United States of America. Washington DC: Government Printing Office. The White House.

(1997) National Security Strategy of United States of America. Washington DC: Government Printing Office. The White House.

(1998) National Security Strategy of United States of America. Washington DC: Government Printing Office. The White House.

(2000) National Security Strategy of United States of America. Washington DC: Government Printing Office. The White House.

(2001) National Security Strategy of United States of America. Washington DC: Government Printing Office. The White House.

(2002) National Security Strategy of United States of America. Washington DC: Government Printing Office. The White House.

(2006) National Security Strategy of United States of America. Washington DC: Government Printing Office. The White House.

(2010) National Security Strategy of United States of America. Washington DC: Government Printing Office. The White House. 
ONUF, N. G. (1989) World of Our Making: rules and rule in social theory an international relations. Columbia: University of California (acesso e-book).

(1998) Constructivism: A user's manual. In: KUBALKOVÁ, V.; ONUF, N.; KOWERT, P. (Ed.) International Relations in a Constructed World. Armonk: M. E. Sharpe, Inc. p.58-78.

ONUF, N. G. \& KLINK, F.F. (1989) "Anarchy, Authority, Rule”. International Studies Quarterly, Vol. 33, No. 2 Jun, pp. 149-173.

O'REILLY, K. P. 2007. Perceiving Rogue States: The Use of the "Rogue State Concept by U.S. Foreign Policy Elites. Foreign Policy Analysis 3 (4):295-315.

Preble, C. (2005). The Bush Doctrine and "Rogue States". Cato Institute-Foreign Service Journal,

REAGAN, R. 1986 The President's News Conference. Ronald Reagan Presidential Library.

Disponível em: http://www.reagan.utexas.edu/archives/speeches/1986/50786a.htm

ROTBERG, R. I. (2007). Worst of the Worst: Dealing with Repressive and Rogue Nations. Washington D.C., Cambridge: Brookings Institution Press and World Peace Foundation.

SAUNDERS, E. N. 2006. Setting Boundaries: Can International Society Exclude "Rogue States"? International Studies Review, Vol. 8 issue 1, pp. 23-54.

SCHMEMANN, S. 1988 German is Seized in Disco Bombing. Special to the New York Times. January 12. Disponível em: http://www.nytimes.com/1988/01/12/world/german-is-seized-indisco-bombing.html

SENN, M. (2008) Wolves in the Woods. The Rogue State Concept from a constructivist perspective. Innsbruck, Univ. Nomos. Germany.

SMITH, D.D. (2006) Deterring America. Rogue States and the Proliferation of Weapons of Mass Destruction. Cambridge University Press.

THOMPSON, Janna (2002)“Is there a thing such as Rogue States?" Published by the Centre for Applied Philosophy and Public Ethics

U.S. Department of State: Townterview With Danish Youth Hosted by TV2 With Johannes Langkilde. Interview with Hillary R. Clinton. Denmark, May 31,2012.

WENDT, Alex.(2007) Social Theory of international relations. Cambridge: Cambridge University Press, pp. 246-312.

285. JSTOR

(1995) "Anarchy is what states make of it", International Security (46),: 391-

ZEHFUSS, Maja. (2001) "Constructivisms in International Relations: Wendt, Onuf, and Kratochwil” in FIERKE, Karin M. \& JORGENSEN, Knud Erik (ed.) (2001) Constructing International Relations: the next generation New York. 


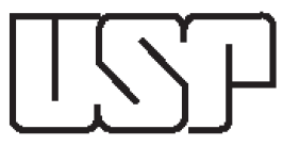

UNIVERSIDADE DE SÃO PAULO

INSTITUTO DE RELAÇÕES INTERNACIONAIS

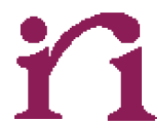

E PÓS-GRADUAÇÃO EM RELAÇÕES INTERNACIONAIS

Karen Katarine Mizuta

ROGUE STATE E ARMAS NUCLEARES: RACIONALIDADE DOS ATORES NA AQUISIÇÃO DE ARMAS NUCLEARES NO PÓS-GUERRA FRIA

São Paulo

2013 


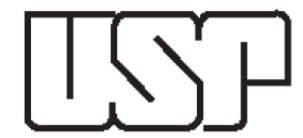

UNIVERSIDADE DE SÃO PAULO INSTITUTO DE RELAÇÕES INTERNACIONAIS

PROGRAMA DE PÓS-GRADUAÇÃO EM RELAÇÕES INTERNACIONAIS

\title{
ROGUE STATE E ARMAS NUCLEARES: RACIONALIDADE DOS ATORES NA AQUISIÇÃO DE ARMAS NUCLEARES NO PÓS-GUERRA FRIA
}

\author{
Karen Katarine Mizuta
}

\begin{abstract}
Segundo artigo apresentado ao Programa de Pós-Graduação em Relações Internacionais do Instituto de Relações Internacionais da Universidade de São Paulo como parte dos requisitos para obtenção do título de Mestre em Relações Internacionais.
\end{abstract}

Orientação: Prof. Dr. Rafael A. D. Villa.

São Paulo 


\section{Rogue State e Armas Nucleares: racionalidade dos atores na aquisição de Armas nucleares no Pós-guerra Fria}

\section{Rogues states: historicidade e percepções}

Nas duas últimas décadas, Washington tem usado o termo rogue state quando se refere a certos países e a certas políticas e condutas adotadas por estes países. Rogue states são frequentemente caracterizados - por tomadores de decisões e certos acadêmicos norteamericanos - como sendo "internamente repressivos, externamente agressivos e regimes imprevisíveis buscando e proliferando tecnologias destrutivas, ameaçando outros países, e minando deliberadamente normas internacionais" (SENN, 2008, p. 19, tradução nossa). Apesar do frequente uso, não há um consenso na literatura sobre o que realmente definiria um Estado como rogue, ou sequer se realmente existiriam.

Acadêmicos, estudiosos do tema, consideram o surgimento do termo como sendo controverso. Robert Litwak (2000) aponta que a ideia da existência de países delinquentes do sistema internacional surge ainda durante a Guerra Fria, nas suas últimas décadas, como forma de designar países com comportamento interno hostil. Termos como "pariah", "outlaw", "renegade regimes" seriam utilizados em referência ao comportamento interno, e somente no pós-Guerra Fria, estes termos sofreriam alteração em seu sentido e o conceito de rogue state surgiria para designar países com comportamento delinquente e agressivo no âmbito internacional. No entanto, Michael Klare, aponta que o termo em si surge como forma de corroborar políticas americanas, justificando-as tanto internamente quanto externamente (KLARE, 1995, p. 25). O termo e consequentemente a sinalização de "novos inimigos" após a queda da União Soviética, criaria dentro do aparato americano um meio do Departamento de Defesa justificar seus gastos e orçamento ao Congresso Nacional, uma vez que gastos com forças militares eram tão altos quanto os da Guerra Fria e a presença militar americana no mundo só crescia.

Deste processo surgiu o que pode ser denominado Doutrina Rogue- a caracterização de países do Terceiro Mundo hostis (ou que pareciam hostis) com grandes forças militares e nascentes capacidades de Armas de Destruição em Massa como rogue states ou outlaws nucleares empenhados em sabotar a ordem mundial prevalecente. Estes regimes são ditos abrigadores de intenções agressivas vis-à-vis seus vizinhos menos poderosos, opositores da "expansão da 
democracia", e serem culpados de contornar normas internacionais contra a proliferação nuclear e química. (KLARE, 1995, p. 26, tradução nossa).

Martin Senn discute o surgimento da ideia de países rogues a partir da década de 1970, porém ainda com a utilização de outros termos. Termos como "rogue", "outlaw", "renegade", "(states) of concern", "pariah", e "axis of evil" (pelo Governo Bush) serviriam para apontar países, os quais os Estados Unidos deveriam focar seus esforços de contenção. Como mencionado anteriormente, comportamentos específicos foram relacionados aos rogue states, apesar de nem todos os rogues states apresentarem estas características comportamentais e alguns países que as apresentam não serem considerados rogue states pelos policy-makers americanos, por motivos políticos. Assim, a busca, posse e proliferação por armas de destruição em massa (ADM), ameaça, subversão e agressão ao sistema internacional, envolvimento com e apoio ao terrorismo, rejeição às normas internacionais, ódio e aversão aos Estados Unidos, imprevisibilidade, irracionalidade e fracasso da dissuasão enquadraria um país como sendo rogue state.

Martin Senn (SENN, 2008, p. 14) aponta que na percepção americana, a combinação entre "radicalismo e tecnologia", nas palavras do ex-presidente Bush, fariam com que os rogue states se tornassem uma grande ameaça, porém uma ameaça de natureza diferente da então proveniente da URSS.

Ao contrário da URSS, acredita-se que os rogue states seriam atores irracionais provavelmente reagindo imprevisivelmente sob pressão e que usariam capacidades de armas de destruição em massa para chantagem e até mesmo para primeiro ataque. Dado a suposição de que os rogue states provavelmente usarão armas de destruição em massa e mísseis balístico, tão breve eles tiverem a capacidade para fazê-lo, estratégia e medidas para lidar com esta ameaça segue a premissa que rogue states devem ser prevenidos de adquirir ou desenvolver tecnologias sofisticadas. (SENN, 2008, p. 14, tradução nossa)

Deste modo, Rogue states são vistos como sendo atores que supostamente tomariam mais riscos, sendo que ADM poderiam, então, ser usadas como armas de ataque - e não para defesa - e consequentemente, medidas de dissuasão não serviriam para contê-los.

De acordo com Senn, o conceito de rogue state serviria para explicar uma identidade adotada e percebida pelos atores. Em seu livro, o autor adota a perspectiva construtivista para 
análise do conceito rogue e procura demonstrar que é através da interação social que a identidade de cada ator é produzida na alteridade. A interpretação dos atores em relação aos outros e ao mundo sofreria influência do próprio mundo e de atores externos, uma vez que os atores não vivem em isolamento. Assim, eles seriam constituídos e moldados por essa interação.

Primeiramente, $e g o$, baseado em sua definição da situação, engaja-se em uma ação que assinala para alter ambos os papeis que ego está planejando tomar na interação e qual papel correspondente este prevê para alter. Na segunda cena, alter interpreta o significado da ação de ego em relação a sua própria percepção da situação. alter, com base em sua interpretação, que pode ter envolvido aprendizado, agora se engaja em uma ação própria. Isto constitui em um sinal para ego da mesma forma que as ações de ego foram para alter. Finalmente, na quarta cena, ego responde. (ZEHFUSS apud SENN, 2008, p. 53, tradução nossa)

Zehfuss argumenta que a identidade dos Estados são instáveis, não porque oscilam no seu conteúdo, mas por serem constituídas de percepções variadas, sendo acionadas uma ou outra de acordo com as circunstâncias.

Segundo as teorias construtivistas, os agentes e a estrutura seriam co-determinados uns pelos outros, sendo construídos e podendo ser modificados pela interação entre eles. Assim, o mundo não seria predeterminado, mas construído à medida em que os atores interagissem através do processo de comunicação, transformando o mundo e a realidade em uma construção social. Os interesses e as preferências dos atores seriam construtos sociais decorrentes de tal interação. A linguagem oral e textual é considerada como importante ferramenta na política internacional; o discurso possui sempre duplo sentido e motivações encobertas vinculadas a uma relação de poder.

Apesar de não descartarem as causas materiais, os construtivistas consideram que as ideias e valores produzem significado à matéria, informando a relação entre o agente e o mundo, por sua vez proporcionando o conhecimento do próprio mundo. A realidade somente faria sentido se agregado algum valor ou informação sobre ela, isto é, "as pessoas agem em relação aos objetos, incluindo outros atores, baseado nos significados que estes objetos possuem para elas” (WENDT, 1995, p. 396). Ao atribuirmos significado à matéria, mostramos que não há autonomia da mesma, senão a percepção sobre ela (ONUF, 1989, cap. 1).

Desta forma, países como Irã, Iraque e Coreia do Norte perceberiam e seriam percebidos pelos Estados Unidos como sendo Estados de comportamento agressivo, principalmente 
destrutivo e ameaçadores de sua integridade e sobrevivência internacional. Esta identidade somente ganha sentido dentro do contex to intersubjetivo criado a partir da interação dos atores.

Do mesmo modo, estes atores são percebidos com agressivos e possíveis revisionistas do status quo internacional, os chamados rogue state são percebidos como atores irracionais com grande tendência a aceitar riscos na tomada de decisão. Sua capacidade material bélica, mesmo que diminuta, adquire "força" uma vez que é percebida como uma grande ameaça por estar em poder de um Estado com comportamento delinquente. Esta percepção de irracionalidade, conjuntamente com a significância das capacidades bélicas, será nosso objeto de discussão a seguir neste artigo.

\section{Rogue state como ator irracional}

A Doutrina de Rogue State promovida pelos Estados Unidos tem como argumento central a ameaça que Estados como Irã e Coreia do Norte representaria para o Sistema Internacional. A percepção destes atores como sendo internacionalmente agressivos e consequentemente com comportamento de profundos revisionistas tem sido o "aspecto central do conceito de rogue state" (SENN, 2008, p. 144, tradução nossa). Os Estados Unidos perceberiam estes Estados como grandes desestabilizadores de sua segurança, sendo este argumento largamente reforçado pelas políticas e retórica adotadas pelos tomadores de decisão norte-americanos. Ao mesmo tempo, "do ponto de vista dos líderes dos rogue states, os Estados Unidos é um ator relevante representando um risco existencial ou mesmo uma ameaça, p. ex. uma potencial ou atual repressão em larga escala na sua capacidade de satisfazer interesses vitais" (SENN, 2008, p. 144, tradução nossa).

Esta doutrina coloca como foco a ameaça provinda de um possível ataque utilizando-se de armas de destruição em massa e tecnologia de míssil balístico. Além disso, (ELAND; LEE 2001, p. 4) "a Doutrina de Rogue States” perpetua a demonização de tais nações sugerindo que eles certamente iriam se comportar no cenário internacional de maneira hostil, uma vez que o termo foi sempre empregado pejorativamente para “(des)qualificar” um Estado. 
De acordo com a perspectiva da política externa americana, a lógica da dissuasão nuclear não teria efeito em se tratando de atores como os rogue states. As ações destes últimos não poderiam ser previstas, uma vez que não seguem a racionalidade dos demais atores do sistema internacional. Como mencionado anteriormente, seriam atores mais propensos a tomarem riscos, a "apostar" com as possibilidades de ação; dessa forma, o uso de armas nucleares seria visto por eles como um recurso para ataque e não para defesa. Consequentemente, por não serem engajados em cálculos lógicos de "custo-benefício", dissuadi-los seria menos provável, conferindo a principal preocupação em relação a obtenção de armas nucleares pelos mesmos.

A visão que o Governo Bush possui em relação aos rogue states aprofunda a ideia já apresentada de irracionalidade destes atores. Aponta-se que o uso de armas nucleares é, para eles, uma opção de recurso para ataque, diferentemente da Guerra Fria na qual as armas nucleares eram vistas como o último recurso para defesa.

Durante a Guerra Fria, especialmente seguinte à crise dos mísseis cubana, nós enfrentamos um status quo em geral, um adversário avesso ao risco. Dissuasão era uma defesa efetiva. Mas dissuasão baseada somente na ameaça de retaliação é menos provável de funcionar contra lideres dos rogue states mais propensos a tomar riscos, apostar com as vidas de seus povos, e a riqueza de suas nações... Na Guerra Fria, armas de destruição em massa eram consideradas armas de último recurso em que seu uso implicaria no risco de destruição daqueles que as usassem. Hoje, nossos inimigos veem as armas de destruição em massa como armas de escolha. Para rogue states, estas armas são instrumentos de intimidação e agressão militar contra seus vizinhos. Estas armas podem também permitir estes Estados a chantagearem os Estados Unidos e seus aliados a nos prevenir de dissuadir ou repelir o comportamento agressivo dos rogue states. Estes Estados também vêm essas armas como o seu melhor meio de superar a superioridade dos Estados Unidos. (NSS, 2002, p. 15, tradução nossa)

Desta forma, depreendemos que um dos argumentos centrais da Doutrina Rogue State tem sido a suposição que tais Estados seriam irracionais e não passíveis de serem dissuadidos. No entanto, "alguns críticos notam que o critério de racionalidade aplicado as estados como Coreia do Norte, Iraque e Irã é muito mais rigoroso que o critério aplicado a União Soviética durante a Guerra Fria" (ELAND;LEE, 2001, p. 4, tradução nossa). Observadores como Robert Joseph acreditam que "a tentativa de classificar os rogue states como irracionais reflete a percebida falta de correto entendimento, necessário para a dissuasão funcionar efetivamente entre estados armados com armas de destruição em massa e mísseis balísticos" (ELAND;LEE, 2001, p. 4, tradução nossa). 
A busca e desenvolvimento de armas de destruição em massa e mísseis balísticos agravam sua imagem como antagonistas e outsiders. "A imagem de "nuclear madman tem sido uma característica constante do conceito de rogue state desde a administração Reagam”, quando a ideia de rogue surge, "embora variando o grau e o impacto nas políticas norte-americanas visà-vis estes Estados” (SENN, 2008, p. 148, tradução nossa).

Em concordância com Joseph, Senn apresenta que a falta de conhecimento e a baixa interação entre a diplomacia americana e dos rogue states seriam um dos motivos para o apontamento dos últimos como irracionais e propensos a aceitar riscos; para o autor, este baixo nível de conhecimento poderia levar a suposições superficiais ou mesmo erradas. Quatro suposições sobre a irracionalidade destes atores são analisadas por Senn e serão apresentadas a seguir (SENN, 2008, p. 158).

A irracionalidade dos rogue states seriam em grande parte percebida como uma consequência das extravagantes personalidades de seus respectivos líderes. Isto é, muitas vezes os líderes dos chamados rogue states são percebidos como antíteses do que supostamente deveria ser um estadista (ocidental). Suas características psicológicas excêntricas (megalomania, aparência bizarra, culto à personalidade) marcam sua imagem; assim, esta suposição teria raízes na percepção de que esses líderes tomariam suas decisões políticas através de impulsos decorrentes de sua personalidade e não de cálculos racionais.

Outra suposição seria a de que a tomada de decisão para o comportamento externo (política externa) seria motivada por ideologias (muitas vezes consideradas radicais) ou por características psicológicas (recaindo sob a característica patológica do líder) e não por motivações de interesses nacional. Assim, a tendência de assumir mais riscos - ou seja, custos altos por pequenos ganhos - levaria a uma imprudência na tomada de decisão, podendo assumir riscos altos de sobrevivência por conquistas de objetivos menores. "A suposição sobre o comportamento do rogue state é, portanto, baseada na analogia de um 'homem-bomba', que valoriza a realização de um objetivo ideológico e/ou religioso acima da sua própria sobrevivência" (SENN, 2008, p. 158-159, tradução nossa); por serem repressivos internamente com suas populações os rogues são percebidos como aceitantes de alto riscos por desmerecer o valor da vida de seus cidadãos. 
Além disso, esta imagem de irracionalidade é aumentada pela percepção Americana de que a tomada de decisão é feita por uma estrutura limitada - unicamente pelo líder ou por uma elite política diminuta - não havendo um debate ou um processo político de barganha interna. Assume-se então um alto risco de decisões errôneas ou mesmo a decisão por políticas ditas irracionais.

O último ponto recai na suposição de que os rogue states ressaltariam estratégias de manipulação de percepções de seus comportamentos internacionais. Eles enfatizariam políticas para aumentar sua capacidade de dissuasão frente ao baixo nível de capacidade material de seus arsenais. Supor causar grande dano àqueles que os ameaçariam se torna um grande instrumento para sua dissuasão.

Juntamente com o último argumento, podemos apresentar a discussão de comportamento irracional feita por Thomas Schelling. Em seu livro Strategy of Conflict, Schelling argumenta que a racionalidade de um indivíduo nem sempre é a mesma do outro. Em uma situação de barganha ou competição, o ator B pode não agir de acordo com a conjetura do ator A, e será percebido pelo ator A como uma escolha/ação irracional. Mas em vez disso, do ponto de vista de $\mathrm{B}$ parece ser a opção racional a fazer; mas durante esta situação de competitividade o comportamento não convencional de $\mathrm{B}$ será percebido como sendo imprevisível, irracional ou até mesmo louco. Como Jonathan Schell afirma

[Schelling argumenta que] se você se propõe a se fazer visivelmente um pouco fora de controle, o inimigo já não seria capaz de imaginar que você possa desistir da guerra nuclear em um ataque de sanidade no último minuto. Eles pensariam que você poderia mergulhar no abismo a despeito de si mesmo. E então eles o temeriam, como esperado...Outra solução, também explorada por Schelling, entre outros, foi o cultivo deliberado da reputação de irracionalidade. Schelling chamou essa política de "racionalidade da irracionalidade". Nesta política, o inimigo acreditaria nas suas ameaças autodestrutivas não porque ele pensa que você pode escorregar em uma casca de banana à beira [do precipício], por assim dizer, mas porque acredita-se que você é lunático o suficiente para ir além do limite deliberadamente. Richard Nixon foi um praticante desta estratégia... Ele a chamou de "teoria do louco". (KIMBALL, 2005)

Depreende-se que este cultivo da reputação de irracional, como mencionado acima, é largamente utilizado pelos chamados rogue states. A imagem de atores irracionais de países como Irã, Coreia do Norte, Líbia e Iraque (na administração de Saddam Hussein) é construída socialmente em duas vias: tanto pelos Estados Unidos, como uma forma de demonizá-los e 
colocá-los como sendo os outsiders do sistema internacional, como por eles próprios, como estratégia de política internacional.

A suposição americana de que os rogue states não seriam passiveis de serem dissuadidos provém da ideia de que a tomada de decisão dentro do aparato político destes países não levaria em conta cálculos racionais, como já mencionado. A deterrence (deterrência) para funcionar necessita de uma comunicação efetiva entre as duas partes e conhecimento por ambos das intenções do outro. A deterrência sugere uma ação estratégica a fim de deter o oponente a realizar algo.

Deterrência é uma estratégia coercitiva. Em outro lugar, eu defini coerção como 'a aplicação potencial ou efetiva da força para influenciar a ação de um agente voluntário'. Quando a ação de um agente pode ser influenciada sem a ameaça da forca, isto envolve consentimento; quando a aplicação da força é tal que o agente não pode mais ser considerado voluntário, isto é controle. (FREEDMAN apud SENN, 2008, p. 150, tradução nossa)

De acordo com Senn, a deterrência por punição é a forma de deterrência na qual o governo americano centra seus esforços para tentar conter ameaças externas. Esta relação caracterizou a relação entre Estados Unidos e União Soviética durante a Guerra Fria: “o ator A detem um ator B de tomar uma ação indesejada ao assinalar que a ação de B vis-à-vis A irá desengatilhar uma reação causando altos (e portanto possivelmente inaceitável) custos para B" (SENN, 2008, p. 151, tradução nossa).

Deste modo, o argumento americano de que os rogue states seriam extremamente perigosos por não poderem ser detidos se armados nuclearmente parece ser falho. Senn afirma que países como Coreia do Norte e Irã "não podem ser assumidos como sendo atores irracionais. Ao contrário, os tomadores de decisão nestes Estados provaram ser bastante hábeis 'ao considerar os benefícios e custos de suas ações"” (SENN, 2008, p. 161, tradução nossa). A analogia com um homem-bomba, então, seria exagerada e incorreta; além disso, as capacidades militares dos rogues são limitadas frente ao arsenal americano, mesmo se adquirido tecnologia suficiente para o desenvolvimento de ADM (SENN, 2008, p. 161-168). 


\section{Programas nucleares do "rogue states"}

Irã

O programa nuclear iraniano sempre foi visto como uma grande contribuição para o aspecto outlaw do país. Signatário do Tratado de Não Proliferação de Armas Nucleares (TNP), oficialmente a cúpula do governo iraniano assegura que seu programa nuclear atende somente ao propósito civil e que o desenvolvimento de armas nucleares contradiz tanto a doutrina religiosa quanto militar.

Ao mesmo tempo, uma decisão em perseguir armas nucleares necessitaria superar obstáculos políticos bem como técnicos. Irã há muito tempo disse que sua intenção é em relação a um programa nuclear pacífico. Líder supremo Ayatollah Ali Khamen denominou as armas nucleares como 'pecado grave', reivindicando que o Irã 'nunca perseguiu e nunca [as] perseguirá'. (ACA, 2013 , p. 6, tradução nossa)

Sob o TNP, a liderança iraniana enfatiza que a aquisição de tecnologia nuclear para fins pacíficos é um direito inalienável e que tal tecnologia promoveria uma importante modernização do país. Além disso, o programa de energia nuclear satisfaria as necessidades crescentes do Irã por energia. Apesar da retórica oficial, alguns pontos do programa iraniano podem gerar dúvidas quanto à estrita natureza civil de seu programa nuclear.

A grande preocupação em relação ao programa nuclear de enriquecimento de urânio é a possibilidade que ele traz de promover a habilidade em produzir material físsil para a construção de armas nucleares, o enriquecimento de urânio a níveis altos (HEU, siga em inglês).

Com seu inicio nos anos 1980, o programa iraniano pode hoje enriquecer urânio em níveis baixos, (low-enriched uranium a 3,5 por cento - LEU) em seus reatores nucleares. De acordo com o relatório da Agência Internacional de Energia Atômica (AIEA), desde Fevereiro de 2010, o Irã tem produzido urânio enriquecido a 20 por cento U-235, alegando ser para o fornecimento de combustível para o Reator de Pesquisa de Teerã, que produz isótopos médicos e para pesquisa em reatores similares.

Embora o enriquecimento de urânio a 20 por cento não é necessariamente um indicativo de uma intenção em produzir armas nucleares, o armazenamento de urânio a este nível é preocupante pois, se o Irã tentar produzir urânio a nível de armamento, este poderia fazê-lo muito mais rápido 
usando urânio enriquecido a 20 por cento que começar com material enriquecido a 3,5 por cento. Enriquecer urânio a 20 por cento constitui em 90 por cento do trabalho necessário para enriquecer a níveis de armamento. (ACA, 2013, p. 6, tradução nossa)

Além do desenvolvimento da tecnologia de enriquecimento de urânio, o Irã possui um programa de desenvolvimento de mísseis balísticos que poderia ser utilizado como um meio de lançamento de ogivas. "De fato, o Irã é suspeito de ter realizado pesquisa e desenvolvimento em como montar uma ogiva nuclear em um míssil e detoná-lo em altura apropriada" (ACA, 2013, p. 12, tradução nossa).

Apesar de o Irã ter capacidade de desenvolver tecnologia para a produção de mísseis de longo-alcance que serviriam para o lançamento de ogivas, avaliações americanas oficiais demonstram que seu programa balístico está voltado para a sofisticação de mísseis balísticos de médio-alcance (ACA, 2013, p. 12).

Apesar de boa parte de suas atividades estarem sob inspeções não anunciadas da AIEA desde 2003 e estarem sob salvaguarda da mesma agência, parte de seu programa não é compartilhado com a AIEA, pois o governo iraniano acusa tanto a agência quanto o Conselho de Segurança da ONU de está-lo privando de um direito de signatário do TNP.

O programa iraniano, no entanto, pelas avaliações feitas ainda não é capaz de ter produzido uma arma nuclear. Porém, a longo prazo essa possibilidade existiria se realmente for o objetivo. As motivações para tanto ainda são mera especulações, pois o discurso oficial não revela essa finalidade. Em documento de 2011, a agência internacional AIEA relatou preocupação com atividades desenvolvidas em território iraniano, reportando a possibilidade de desenvolvimento de ogivas de pequeno porte.

A informação indica que o Irã tem executado as seguintes atividades relevantes ao desenvolvimento de dispositivos nucleares explosivos: •Esforços, alguns bem sucedidos, em adquirir equipamento e materiais nucleares relacionados e de uso dual, por indivíduos e entidades relacionadas a militares; •Esforços para desenvolver caminhos não declarados para desenvolvimento de material nuclear; - A aquisição de informação de desenvolvimento de armas nucelares e documentação de redes de suprimentos nucleares clandestinos; -Trabalhar no desenvolvimento de design original de arma nuclear incluindo o teste de componentes. (IAEA, 2011, p. 8, tradução nossa) 
Este documento recebeu informações de pesquisas de inteligência dos Estados Unidos, de alguns outros países e da própria agência. Na época, o Irã negou programas de desenvolvimento de ogivas e acusou a AIEA de ter baseado seu relatório em informações fabricadas. No mais recente relatório desta mesma agência, o tom de preocupação permanece em relação a necessidade de engajamento iraniano nas verificações dos inspetores da AIEA, porém não há a menção efetiva, como no relatório mencionado acima, de busca por obtenção de armas nucleares.

Enquanto a agência continua a verificar o não-desvio do material nuclear declarado nas instalações nucleares e locais fora das instalações (LOF) declaradas pelo Irã sob seu Acordo de Salvaguarda, como Irã não está fornecendo a cooperação necessária, incluindo a não implementação do Protocolo Adicional, a Agência está inapta a fornecer garantia confiável sobre a ausência de material nuclear não declarado e atividades no Irã, e portanto, concluir que todo o material nuclear no Irã está em atividades pacíficas. (IAEA, 2013, p. 12, tradução nossa)

Ao longo dos anos o Irã tem sofrido sanções não somente por parte da ONU, mas também unilateralmente dos Estados Unidos. Desde 1979, os Estados Unidos mantém longas e amplas sanções e medidas que proíbem largamente o comércio entre os americanos e o Irã. Inúmeras sanções e atos foram vistos durante os últimos anos como forma de retaliar as ações do governo iraniano. Alguns destes importantes atos são o Iran-Iraq Arms Nonproliferation Act of 1992 e o Iran-North Korea-Syria Nonproliferation Act de 2000, impondo sanções em instituições estrangeiras que proveria o Irã com tecnologia de armas de destruição em massas ou armas convencionais "desestabilizadoras" e autorizando sanções em indivíduos ou corporações que estão assistindo o programa de armas de destruição em massa iraniano, respectivamente.

Grandes proibições relacionadas a restrições financeiras e comerciais têm sido aplicadas:

desde 2008 todas as instituições financeiras sob jurisdição americana também estão proibidas de executar as chamadas transações 'U-turn'. Esta proibição previne bancos americanos de completar transações com bancos estrangeiros de agir em nome de entidades iranianas. Esta regulamentação do Departamento do Tesouro efetivamente corta o Irã do sistema financeiro americano, além de isolá-los ao negar ao Irã a habilidade de conduzir transações em dólar americano, a moeda dos mercados de petróleo (ACA, 2013, p. 12, tradução nossa). 
Muitos analistas afirmam que qualquer negociação com Teerã deve exigir o fim do programa iraniano de enriquecimento de urânio. Embora a maioria dos tomadores de decisões americanos partilha do "posicionamento de enriquecimento zero", isto não tem obtido muito apoio da comunidade internacional.

Países em desenvolvimento, incluindo parceiros-chave dos Estados Unidos, como Índia, têm emitido com frequência declarações em apoio aos direitos do Irã em conduzir um programa nuclear pacífico. Um esforço diplomático Brasileiro-Turco com o Irã concluiu em declaração de Maio de 2010 que o Irã tem o direito sob o TNP de "desenvolver pesquisa, produção e uso de energia nuclear (bem como o ciclo do combustível nuclear incluindo as atividades de enriquecimento) para propósitos pacíficos sem discriminação.” (ACA, 2013, p. 25, tradução nossa)

Além disso, mesmo se o Irã conseguisse adquirir armas nucleares, não se pode acreditar que este teria como objetivo usá-los para um ataque massivo. "O possível programa nuclear iraniano serviria primeiramente como um meio de assegurar sua sobrevivência em vista da insegurança existente" (SENN, 2008, p. 97, tradução nossa) em torno de sua região.

\section{Coreia do Norte}

Desde os primeiros dias de sua existência, a Coreia do Norte tem sido percebida como uma ameaça a comunidade mundial. Sua imagem como "inimigo" tem se perpetuado por sua oposição a Coreia do Sul e seu aliado os Estados Unidos. Lidar com a República Democrática Popular da Coreia, como prefere ser denominada, tem sido um dos maiores desafios na política internacional no pós-guerra Fria.

Os programas nuclear e balístico norte-coreanos ultrapassaram diferentes períodos de engajamento e rejeição de acordos internacionais. Em 1985, a Coreia do Norte aderiu ao Tratado de Não-Proliferação de armas nucleares (TNP), apesar de não ter completado todas as salvaguardas necessárias pelo AIEA. Nos anos seguintes, a Coreia do Norte concordou em ter inspeções da agência internacional em seu programa, apresentando relatórios sobre suas atividades nucleares. No entanto, desacordos em como seriam essas inspeções levam a liderança 
norte-coreana a declarar suas intenções em se retirar do tratado. Esta atitude provocou uma crise nuclear em que os olhares da comunidade internacional, principalmente os Estados Unidos se voltariam. Poucas semanas após suas declarações em 1993, Pyongyang cancela sua retirada e compromete-se a pôr fim na busca por armas nucleares em troca de ajuda.

Os anos seguintes foram marcados pelo engajamento a uma conjuntura mais cooperativa. As relações entre Pyongyang, Washington e Seul passaram por uma fase na qual a retórica hostil diminuiu. Mas em 2002, outra crise nuclear emergiu na península com a admissão pela Coreia do Norte que esta tinha buscado secretamente desenvolver projetos e pesquisa para o enriquecimento de urânio. Após sua admissão, Pyongyang declarou oficialmente sua retirada do TNP em 2003, banindo os inspetores do AIEA do país e proibindo novas inspeções. Novos esforços diplomáticos foram sinalizados como o Six-Party Talks ${ }^{10}$; em 2005, a Coreia comprometeu-se em abandonar "todas as armas nucleares e programas nucleares existentes" e retornar ao TNP.

Em 2006, no entanto, o país conduziu um teste nuclear subterrâneo tendo como sobre o qual seu Ministro de Relações Estrangeiras declara "que seu teste nuclear foi inteiramente atribuível às ameaças nucleares americanas, sanções e pressões" adicionando que a Coreia do Norte "foi compelida a provar substancialmente a posse de armas nucleares para proteger sua soberania" (ACA, 2013).

Roland Bleiker assinala que a diplomacia norte-coreana arriscada apresenta um grande perigo (BLEIKER, 2003, p. 719); no entanto, o autor revela que não são somente as ameaças vindas das atividades coreanas que devem ser ressaltadas, as "atitudes de confronto e militares com as quais alguns dos atores regionais e globais, notadamente os Estados Unidos, procuram conter a situação" apresenta perigo igualmente (BLEIKER, 2003, p. 719). Para o autor, o fato de a política externa Americana ter sido guiada pelo fenômeno dos chamados rogue states, faz com que o ocidente em especial tenha a imagem unilateral da Coreia do Norte, percebida como sendo um outlaw, como dito anteriormente. Isto é, ao construir a imagem da Coreia do Norte

\footnotetext{
${ }^{10}$ Negociações envolvendo China, Japão, Coreia do Norte, Rússia, Coreia do Sul e Estados Unidos
} 
como sendo um rogue state impediu um entendimento adequado e uma possível resolução ao problema.

A retórica americana dos rogue states demoniza o país colocando o sob uma cruzada a nível mundial. Ao trazer a perspectiva norte-coreana sobre a crise nuclear mencionada acima, Bleiker aponta o papel dos Estados Unidos na dinâmica da crise. Sobre a "primeira crise" em 1993/1994, baseado nas pesquisas de Leon Sigal, o autor enfatiza como a diplomacia coerciva trouxe a Coreia do Norte à beira da guerra, documento sobre a diplomacia nuclear americana em relação a Coreia do Norte mostraram um "[...] padrão da política externa americana que desencoraja a cooperação e ao invés, promove 'uma abordagem de crime-e-punição' na qual constitui a Coreia do Norte sobre tudo como um rogue state ameaçador" (BLEIKER, 2003, p. 722, tradução nossa). Além disso, ameaças nucleares americanas a Coreia do Norte não somente vai contra os acordos de 1994, mas diretamente viola "o regime de não-proliferação internacional, o qual afirma que os 'estados sem armas nucleares não devem ser ameaçados por aqueles que as possuem"” (BLEIKER, 2003, p. 728, tradução nossa).

Em relação a segunda crise, podemos ter o mesmo discernimento concernente as atitudes tomadas. Como Bleiker relembra, não é negar as atividades nucleares norte-coreanas ou os fatos, mas procurar demonstrar que como todas as crises, esta surgiu da interação de percepções de ameaças de ambos os lados, ações e reações.

Os pronunciamentos durante o governo Bush trazem a percepção da Coreia como inimiga e grande agressora do sistema internacional. O apontamento da Coreia do Norte como sendo um rogue state, e então, um outsider não merecedor do respeito internacional dificulta a possibilidade de engajamento em um diálogo.

A retórica do Mal, usada ao falar dos rogue states, move o conceito de rogue states no domínio da irracionalidade. O Mal é em essência um termo de condenação de um fenômeno que não pode nem ser totalmente compreendido ou dirigido de outra forma que através de formas militares de dissuasão e retaliação (BLEIKER, 2003, p. 732, tradução nossa).

O autor continua

Especialistas em tecnologias militares desempenharam um papel essencial em construir a Coreia do Norte como uma ameaça e em reduzir ou eliminar do nosso alcance as ameaças emanadas dos Estados Unidos e da Coreia do Sul em relação ao Norte (BLEIKER, 2003, p. 734, tradução nossa). 
[...] A imagem da Coreia do Norte como o Mal e um rogue state imprevisível está tão profundamente arraigado que qualquer crise pode ser facilmente atribuída às ações problemáticas de Pyongyang (BLEIKER, 2003, p. 734, tradução nossa).

No início deste ano, outro teste nuclear foi conduzido pela Coreia do Norte e detectado pelo Organização de Tratado de Interdição Completa de Ensaios Nucleares (CTBTO, sigla em inglês). Novamente, o governo norte-coreano atribuiu este novo teste como reação às medidas americanas adotadas contra o primeiro. Sua divulgação foi feita através Agência Central de Notícias Coreanas (KCNA),

O campo científico da defesa nacional da RDPC obteve êxito no seu terceiro teste nuclear subterrâneo no local para teste nucleares subterrâneos na parte norte da RDPC nesta terça-feira. $\mathrm{O}$ teste foi conduzido como parte de medidas práticas de oposição para defender a segurança e soberania do país face aos atos ferozes e hostis dos Estados Unidos que violou desenfreadamente o direito legítimo norte-coreano de lançar satélite com objetivos pacíficos. [...] Os testes nucleares irão encorajar grandemente o exército e o povo da RDPC nos seus esforces de construir uma nação próspera com o mesmo espírito e impetuosidade como exibido em conquistar espaço, e oferecer uma importante ocasião em assegurar paz e estabilidade na Península Coreana e região. (KCNA, 2013, tradução nossa)

O que se seguiu a esta demonstração do governo norte-coreano foi uma grave tensão na península coreana que ainda persiste. Analistas internacionais especulam ainda sobre a verdadeira motivação coreana em adquirir armas nucleares. Poucas ainda são as certezas quanto ao conhecimento e as percepções são restritas.

John Swenson-Wright considera que as motivações coreanas poderiam ser tanto de ordem interna quanto externa. Uma das suas primeiras considerações é o fator unificador que a retórica beligerante norte-coreana pode ter nacionalmente. Ao criar uma sensação de crise internacional, pode-se gerar uma maior unidade nacional e possivelmente consolidar um regime sob um novo comando. Kim Jong-un poderia estar criando a oportunidade de se consolidar como líder, passando uma imagem tão forte a sua população quanto foi seu pai Kim Jong-il. Ajudas econômicas e humanitárias poderiam ser o outro foco das atividades coreanas. Manobras diplomáticas para a ajuda financeira perpassariam a retórica agressiva. Uma terceira possibilidade seria a provocação de uma possível crise entre os Estados Unidos e seu aliado, a Coreia do Sul quando um novo presidente assume neste país. Além disso, um impasse com a 
comunidade internacional proporcionou justificativas do lado norte-coreano em cortas linhas de comunicação com o sul e demais atividades como reativação das instalações de processamento de urânio. Por fim, ao induzir uma crise o norte pode forçar negociar questões além da nuclear diretamente com a administração Obama, como oportunidade de comércio (SWENSONWRIGHT, 2013).

\section{Considerações Finais}

A rotulação de rogue state a certos países perpetua a demonização destas nações e sugere que estes países em particular irão agir de maneira hostil. Da mesma forma, a percepção que estes atores são irracionais e mais propensos a tomar riscos dissemina a ideia de que eles não são passíveis de serem dissuadidos em caso destes adquirirem armas de destruição em massa.

Esta suposição demonstra a falta de conhecimento e o correto entendimento entre os Estados Unidos e os chamados rogue states. Senn evidencia que a baixa interação diplomática americana em relação a estes países, especialmente Irã e Coreia do Norte, poderia levar a suposições superficiais e até mesmo errôneas.

Os Estados Unidos não mantém embaixada em Pyongyang dificultando ainda mais as negociações e o relacionamento entre estes dois países. Esta situação prevalece desde a formação da Coreia do Norte em 1953, com o armistício que dividiu a península coreana Da mesma forma, as relações diplomáticas com o Irã são inexistentes desde 1979.

Assim, os rogue states ressaltariam estratégias de manipulação de percepções de seus comportamentos internacionais. Eles enfatizariam políticas para aumentar sua capacidade de dissuasão frente ao baixo nível de capacidade material de seus arsenais. Supor causar grande dano àqueles que os ameaçariam se torna um grande instrumento para sua dissuasão.

A partir da análise dos programas nucleares do Irã e Coreia do Norte pode-se dizer que cultivo da reputação de irracional é, por vezes, utilizado pelos chamados rogue states. A imagem de atores irracionais, do “nuclear madman”, de países como Irã, Coreia do Norte, Líbia e Iraque (na administração de Saddam Hussein) é construída socialmente em duas vias: tanto pelos 
Estados Unidos, como uma forma de demonizá-los e colocá-los como sendo os outsiders do sistema internacional, como por eles próprios, como estratégia de política internacional.

Desta forma, países como Irã, Iraque e Coreia do Norte perceberiam e seriam percebidos pelos Estados Unidos como sendo Estados de comportamento agressivo, principalmente destrutivo e ameaçadores de sua integridade e sobrevivência internacional. Esta identidade somente ganha sentido dentro do contexto intersubjetivo criado a partir da interação dos atores.

Sua capacidade material bélica, mesmo que diminuta, adquire "força" uma vez que é percebida como uma grande ameaça por estar em poder de um estado com comportamento delinquente. Ao atribuir significado - estar em posse de um ator irracional, delinquente, imprevisível - a matéria - o programa nuclear, mesmo que ainda não se tenha produzido armas nucleares - se torna um grande desafio para o cenário internacional, uma vez que são as percepções sobre a as capacidades materiais e sobre o outro que estabelecem o nosso entendimento sobre o mundo. 


\section{REFERÊNCIAS}

ABRAHMS, Max "When Rogues defy Reason: Bashar's Syria” Fall 2003 Meforum (Middle East Forum); In: http://www.meforum.org/562/when-rogues-defy-reason-bashars-syria.

ACA (ARMS CONTROL ASSOCIATION) 2013, Solving the Iranian Nuclear Puzzle.

BARROSO, Juliana L. V.. Análise do contexto intersubjetivo: A Política Diplomática de promoção da democracia dos Estados Unidos para a América Latina no pós-Guerra fria. (USP, 2010)

BLEIKER, Roland 2003. A rogue is a rogue is a rogue. US foreign policy and the Korean nuclear crisis, International Affairs 79,v. 4, 719-737.

BLUM, William. Rogue State. A Guide to the World's Only Superpower. (London et al. Zed Books, 2002)

BOYS, J. D. 2005. The dual containment of rogue states. Nth Position Website

CHOMSKY, N. 2000. Rogue States: The Rule of Force in World Affairs.

ELAND, I., \& LEE, D. 2001. The Rogue State Doctrine and National Missile Defense. Cato Institute-Foreign Policy Briefing, 9 de March, v 13.

HENRIKSEN, T. H. 2001. The Rise and Decline of Rogue States. Journal of International Affairs, pp. 349-371.

HERRING,E. (2000) "Rogue Rage: Can we prevent mass destruction?" Journal of Strategic Studies, 23, n॰1, p.184-212.

HOYT, Paul D. 2000. The "Rogue State" Image in American Foreign Policy. Global

Society 14 (2).

INTERNATIONAL ATOMIC ENERGY AGENCY, 2012. Application of Safeguards in the Democratic People's Republic of Korea. Disponível em: http://www.iaea.org/About/Policy/GC/GC56/GC56Documents/English/gc56-11_en.pdf

IAEA (INTERNATIONAL ATOMIC ENERGY AGENCY) 2007 Chronology of Key Events- Iran Disponível em:http://www.iaea.org/newscenter/focus/iaeairan/iran_timeline4.shtml

2011. Implementation of the NPT Safeguards Agreement and relevant provisions o

Security Council resolutions in the Islamic Republic of Iran. Disponível em http://www.iaea.org/Publications/Documents/Board/2011/gov2011-65.pdf

2013. Implementation of the NPT Safeguards Agreement and relevant provisions o

Security Council resolutions in the Islamic Republic of Iran. Disponível em:

http://www.iaea.org/Publications/Documents/Board/2013/gov2013-6.pdf 
2013. Chronology of Key Events- DPRK. Disponível em http://www.iaea.org/newscenter/focus/iaeadprk/chrono_jan2013.shtml\#march13

KCNA 2013 Report on Successful 3rd Underground Nuclear Test, Pyongyang, February 12 http://www.kcna.co.jp/index-e.htm

KIMBALL, Daryl. Chronology of U.S.-North Korean Nuclear and Missile Diplomacy, Arms Control Association, in http://www.armscontrol.org/factsheets/dprkchron\#2002.

KIMBALL, Jeffrey 2005. Did Thomas C. Schelling Invent the Madman Theory? http://hnn.us/articles/17183.html

KLARE, M. 1995. Rogue State and Nuclear outlaws: America's search for a new foreign policy. Hill and Wang, New York.

KRATOCHWIL, Friedrich V. 1989. "Constructivism as an approach to Interdisciplinary Study" in FIERKE, Karin M. \& JORGENSEN, Knud Erik (ed.) 2001. Constructing International Relations: the next generation, New York.

LITWAK, R. ( 2000) Rogue States and U.S. Foreign Policy:Containment After the Cold War. Woodrow Wilson International Center for Scholars. Washington, D.C.

2001. What is in a name? The Changing Foreign Policy Lexicon. Journal of International Affairs , pp. 375-392.

LAKE, A. (v.73 de March/April de 1994). Confronting Backlash States. Foreign Affair.

MISLAN, D. B. 2007. Reality, not Rhetoric: The Rogue State label in American Foreign Policy. International Studies Association (Annual Meeting). Chicago,Illinois

NSSUSA 2002. National Security Strategy of United States of America. Washington DC: Government Printing Office. The White House.

2006. National Security Strategy of United States of America. Washington DC: Government Printing Office. The White House.

ONUF, N. G. 1989. World of Our Making: rules and rule in social theory an international relations. Columbia: University of California (acesso e-book).

1998. Constructivism: A user's manual. In: KUBALKOVÁ, V.; ONUF, N.; KOWERT, P. (Ed.) International Relations in a Constructed World. Armonk: M. E. Sharpe, Inc. p.58-78.

ONUF, N. G. \& KLINK, F.F. 1989. "Anarchy, Authority, Rule". International Studies Quarterly, Vol. 33, No. 2 Jun, pp. 149-173.

O'REILLY, K. P. 2007. Perceiving Rogue States: The Use of the "Rogue State Concept by U.S. Foreign Policy Elites. Foreign Policy Analysis 3 (4):295-315.

Preble, C. (2005). The Bush Doctrine and "Rogue States". Cato Institute-Foreign Service Journal,

ROTBERG, R. I. 2007. Worst of the Worst: Dealing with Repressive and Rogue Nations. Washington D.C., Cambridge: Brookings Institution Press and World Peace Foundation. 
SAUNDERS, E. N. 2006. Setting Boundaries: Can International Society Exclude "Rogue States"? International Studies Review, Vol. 8 issue 1, pp. 23-54.

SCHELLING, T C 1960. Strategy of Conflict. Harvard University Press.

SENN, M. 2008. Wolves in the Woods. The Rogue State Concept from a constructivist perspective. Innsbruck, Univ. Nomos. Germany.

SMITH, D.D. 2006. Deterring America. Rogue States and the Proliferation of Weapons of Mass Destruction. Cambridge University Press.

SWENSON-WRIGHT, J. 20013. Viewpoint: What does Pyongyang want? Disponível em:

http://www.bbc.co.uk/news/world-asia-22902119

THOMPSON, Janna 2002“Is there a thing such as Rogue States?” Published by the Centre for Applied Philosophy and Public Ethics

U.S. Department of State: Townterview With Danish Youth Hosted by TV2 With Johannes Langkilde. Interview with Hillary R. Clinton. Denmark, May 31,2012.

WENDT, A. 2007. Social Theory of international relations. Cambridge: Cambridge University Press, pp. 246-312.

285. JSTOR

1995. "Anarchy is what states make of it", International Security (46),: 391-

ZEHFUSS, Maja. 2001. "Constructivisms in International Relations: Wendt, Onuf, and Kratochwil" in FIERKE, Karin M. \& JORGENSEN, Knud Erik (ed.) (2001) Constructing International Relations: the next generation New York. 